NBER WORKING PAPER SERIES

\title{
JOB DISPLACEMENT AND JOB MOBILITY: THE ROLE OF JOBLESSNESS
}

\author{
Bruce Fallick \\ John C. Haltiwanger \\ Erika McEntarfer \\ Matthew Staiger \\ Working Paper 29187 \\ http://www.nber.org/papers/w29187 \\ NATIONAL BUREAU OF ECONOMIC RESEARCH \\ 1050 Massachusetts Avenue \\ Cambridge, MA 02138 \\ August 2021
}

The research program of the Center for Economic Studies (CES) produces a wide range of economic analyses to improve the statistical programs of the US Census Bureau. Many of these analyses take the form of CES research papers. The papers have not undergone the review accorded Census Bureau publications and no endorsement should be inferred. Any opinions and conclusions expressed herein are those of the authors and do not necessarily represent the views of the U.S. Census Bureau, the Federal Reserve Bank of Cleveland, the Federal Reserve System, or the National Bureau of Economic Research. All results have been reviewed to ensure that no confidential information has been disclosed. Associated Disclosure Review Board release numbers are DRB-B0040-CED-20190411, DRB-B0067-CED-20190718, and CBDRB-FY21CED006-0001. Republication in whole or in part must be cleared with the authors. John Haltiwanger was a part-time Schedule A employee at Census at the time of the writing of this paper.

NBER working papers are circulated for discussion and comment purposes. They have not been peer-reviewed or been subject to the review by the NBER Board of Directors that accompanies official NBER publications.

(C) 2021 by Bruce Fallick, John C. Haltiwanger, Erika McEntarfer, and Matthew Staiger. All rights reserved. Short sections of text, not to exceed two paragraphs, may be quoted without explicit permission provided that full credit, including $\odot$ notice, is given to the source. 
Job Displacement and Job Mobility: The Role of Joblessness

Bruce Fallick, John C. Haltiwanger, Erika McEntarfer, and Matthew Staiger

NBER Working Paper No. 29187

August 2021

JEL No. E32,J3,J63

\section{ABSTRACT}

Who is harmed by and who benefits from worker reallocation? We investigate the earnings consequences of changing jobs and find a wide dispersion in outcomes. This dispersion is driven not by whether the worker was displaced, but by the duration of joblessness between job spells. Job movers who experience joblessness suffer a persistent reduction in earnings and tend to move to lower-paying firms, suggesting that job ladder models offer a useful lens through which to understand the negative consequences of job separations.

Bruce Fallick

Federal Reserve Bank of Cleveland

Cleveland, OH 44101-1387

Bruce.Fallick@clev.frb.org

John C. Haltiwanger

Department of Economics

University of Maryland

College Park, MD 20742

and NBER

haltiwan@econ.umd.edu
Erika McEntarfer

U.S. Census Bureau

Center for Economic Studies

4600 Silver Hill Road

ACSD HQ-5K179

Washington, DC 20233

erika.mcentarfer@ census.gov

Matthew Staiger

Department of Economics

University of Maryland

College Park, MD 20742

mstaiger@umd.edu 


\section{Introduction}

The U.S. labor market is highly dynamic, with millions of workers changing jobs every month. A large literature has shown that workers both benefit from and are harmed by these dynamics. On one hand, workers generally reap positive benefits from job-to-job moves, allowing them to sort into better matches and experience positive earnings growth (Topel and Ward, 1992). On the other hand, research on displaced workers finds that job separations result in persistent earnings losses (Jacobson, LaLonde, and Sullivan, 1993a; hereafter referred to as JLS). These two perspectives on the consequences of labor market dynamics are not necessarily in conflict but largely remain siloed from one another in the literature. ${ }^{1}$

Our goal in this paper is to reconcile these disparate views on the consequences of changing jobs. To do this we study the earnings dynamics of all job changers and modify the standard displaced worker empirical model to allow outcomes to vary by the duration of jobless spells as well as the growth rate of the origin firm. We show that earnings losses of displaced workers are not specific to displacement events per se; rather, they are common to all attached job changers. ${ }^{2}$ Earnings losses are instead driven by job changers who experience prolonged jobless spells. In other words, heterogeneity in outcomes for job changers is driven by jobless duration between job spells with little explanatory power from the health of the origin firm. Job changers with minimal joblessness move to higher paying jobs, while those who face a prolonged period of joblessness move to lower paying jobs and suffer persistent earnings losses. Our findings help reconcile the divergent findings on the earnings consequences from job change: inclusion of workers with longer nonemployment spells is a key reason the displaced worker literature finds job separations generally harm workers, while the job mobility literature, with a focus on direct job-to-job moves, finds that workers benefit. ${ }^{3}$

\footnotetext{
${ }^{1}$ Other papers in the displaced worker literature include Schoeni and Dardia (2003); Couch and Placzek (2010); von Wachter, Song and Manchester (2009); and Davis and von Wachter (2011). More recent papers on job-to-job moves include Brown, Haltiwanger, and Lane (2006); Haltiwanger, et al. (2018a, 2018b); and Liu (2019).

${ }^{2}$ Much of the displaced worker literature uses mass layoff events to identify displaced workers and we use this same approach here. On the use of firm distress as an indicator of displacement, see Flaaen, Shapiro, and Sorkin (2019) and von Wachter, Handwerker, and Hildreth (2009).

${ }^{3}$ Another key distinction is the focus on attached prime age workers in the displacement literature. In keeping with that literature, we focus our analysis here on prime age workers with at least three years job tenure. As we discuss later in the paper, earnings gains from job change are largest for younger highly-mobility workers, so we would expect to find smaller earnings gains from direct job-to-job moves in our sample.
} 
Why is the length of the jobless spell predictive of earnings losses following changing jobs? Our findings suggest that job ladder models offer a useful framework for understanding this relationship. Measuring employer pay premiums with an AKM decomposition of earnings, we find that direct job-to-job flows yield movements up the job ladder; in contrast, workers tend to move down the job ladder when they experience extended jobless spells. ${ }^{4}$ Worker heterogeneity, skill depreciation, or local labor market conditions could also plausibly drive an observed relationship between earnings losses and the length of the jobless spell. However, we find little evidence to support these other factors.

Our finding that earnings losses for all job changers are driven by movements down the job ladder is consistent with other research indicating that earnings losses of displaced workers are, in part, attributable to movements to lower-paying firms (Schmieder, von Wachter, and Heining, 2020; Fackler, Müller, and Stegmaier, 2017; Raposo, Portugal, and Carneiro, 2021; Lachowska, Mas, and Woodbury, 2020; Moore and Scott-Clayton, 2019). Our results are most comparable to those of Schmeider, von Wachter, and Heining (2020), who find that displaced workers who spend more time in nonemployment fall further down the job ladder. ${ }^{5}$ Our results indicate that it is not only displaced workers who fall farther down the ladder as duration between job spells increases but job changers from all firms generally. Since displaced workers are only a small share of total job changers, this suggests a need for a more general framework for how job transitions through nonemployment lead to earnings losses. The theoretical models developed by Jarosch (2015), Krolikowski (2017), and Jung and Kuhn (2019) do interpret the earnings losses of displaced workers using models of the labor market that produce job ladders. However, these models cannot explain why the duration of nonemployment is so strongly related to earnings losses and movements down the job ladder. Extending existing models to explain this relationship, and why it is present for workers who separate and change jobs from both distressed and non-distressed firms, should be a priority for future research.

\footnotetext{
${ }^{4}$ AKM refers to the Abowd, Kramarz, and Margolis (1999) decomposition.

${ }^{5}$ Our finding that job separators who experience joblessness have greater earnings losses is consistent with papers finding that displaced workers who experience joblessness in the United States (Addison and Portugal, 1989) and Europe (Portugal, Carneiro and Portugal, 2006; Hijzen, Upward, and Wright, 2010; Bender et al., 2002) have greater earnings losses. These papers did not explore the role of the job ladder or whether separators from non-distressed firms experienced a similar earnings penalty if they transitioned through nonemployment before starting a new job. Our finding that attached job movers who find jobs within one quarter experience minimal earnings losses also resembles the 'alpha' type workers in Gregory, Menzio, and Wiczar (2021), who create a taxonomy of worker attachment types also using the LEHD data.
} 
Although we find job changers have similar earnings losses conditional on jobless duration, one might expect displaced workers would have longer spells of joblessness. ${ }^{6}$ However, we find that displaced workers do not experience longer jobless spells than other job changers. This finding may seem at odds with other research that finds that separators from distressed firms are relatively more likely to be laid off than to quit (Davis, Faberman, and Haltiwanger, 2006 and 2012), and that workers who are laid off are relatively more likely to become unemployed (Elsby, Hobijn, and Sahin, 2010). This tension is resolved by noting, first, we focus on workers who change jobs - a category of workers that excludes recalls - and second, our administrative data only allow us to observe periods of nonemployment, not of unemployment.

There remains the question as to why we find such similar outcomes for job changers from distressed and non-distressed firms. One possibility is that there exists a common mechanism by which joblessness results in earnings losses, a mechanism that is largely independent of the circumstances leading to the job change. ${ }^{7}$ This would be consistent with research that finds a causal negative effect of joblessness on labor market outcomes (Schmieder, von Wachter, and Bender, 2016; Maestas, Mullen, and Strand, 2015). However, unobserved heterogeneity potentially on multiple dimensions complicate this simple explanation. First, job separations that do not coincide with mass layoff events are more likely to be the result of decisions made by the individual worker reflecting individual circumstances. ${ }^{8}$ Second, to remain in nonemployment after a job separation for a period up to eight quarters may also reflect individual circumstances, and these circumstances may also imply that such workers reenter the workforce in jobs with lower wage rates or fewer hours.

To address these concerns, following JLS and the subsequent literature, all of our specifications control for individual fixed effects and we also consider specifications with individual specific time trends. The robustness of our results to the inclusion of individual fixed effects and individual-specific time trends goes some way to alleviating concerns about heterogeneity across workers driving our results. We also explore a number of additional exercises

\footnotetext{
${ }^{6}$ Our findings stand in contrast to JLS who did find differences in the earnings consequences between separators from distressed and non-distressed firms. We believe the JLS results on this point are particular to their sample, Pennsylvania workers during a period of a massive decline in the U.S. Steel industry. Our sample is much larger in terms of states and years of coverage.

${ }^{7}$ See Carrington and Fallick (2017) for a recent assessment of the sources of earnings loss for displaced workers.

${ }^{8}$ For example, Flaaen, Shapiro, and Sorkin (2019) find that a much larger proportion of separators from non-distressed than from distressed firms give a reason for separation when surveyed that may reflect workers' choices.
} 
that lead us to doubt that the relationship between earnings losses and the duration of nonemployment is driven by heterogeneity across workers. First, our main findings hold within demographic groups that we would expect to have stronger or weaker degrees of attachment to the labor force, and thus for which we are less or more concerned about the role of worker choice. Second, because the nature of separations that yield a job change is likely to be different at different points in the business cycle, we would expect the relevant heterogeneity to differ as well. However, our main results hold across a large range of macroeconomic conditions in the quarter of separation. ${ }^{9}$

A key feature of our analysis is that we focus on job changers who have strong labor force attachment. Consistent with the displaced worker literature, we focus on separations of longtenured workers that yield a change in employer within eight quarters. Put simply, we interpret our findings as providing insights about the consequences of job changes for highly attached workers in previously stable job matches. This focus on attached job changers distinguishes our work from other papers in the job mobility literature. In particular, Haltiwanger, Hyatt, and McEntarfer (2018b) find that younger workers drive much of the upward-mobility (and corresponding earnings gains) from job-to-job moves. Given this context it not surprising that we find weaker earnings gains from job-to-job moves among our sample of highly attached workers.

This paper proceeds as follows. Section II describes the data and Section III discusses the measurement methodology for classifying job separations. Section IV presents descriptive statistics. Section V presents our main estimates of earnings losses for distressed and nondistressed separators. Section VI presents our estimates of the predicted duration of nonemployment for distressed and non-distressed separators. Section VII explores various explanations for our main findings including the role of the job ladder. Section VIII concludes.

\section{Data}

We analyze the employment and earnings consequences of changing jobs using linked employer-employee from the Longitudinal Employer-Household Dynamics (LEHD) program. The LEHD data is produced by the U.S. Census Bureau and includes quarterly earnings records collected by state-level unemployment insurance (UI) programs linked to establishment-level Quarterly Census of Employment and Wages (QCEW) data. State-level data availability varies

\footnotetext{
${ }^{9}$ Couch, Jolly, and Placzek (2011) and Davis and von Wachter (2011) also examine how losses vary over the cycle.
} 
by year, as states began sharing UI and QCEW data with the Census Bureau at different times, and states occasionally drop out of the data-sharing partnership. See Abowd, Haltiwanger, and Lane (2004) and in Abowd et al. (2006) for detailed discussion of the LEHD; a brief description follows.

State-level unemployment insurance (UI) data contain quarterly earnings for employees covered by state UI systems, over 96 percent of private-sector employment. ${ }^{10}$ A firm, as defined in this analysis, is a collection of workers who share a common unemployment insurance system identifier. ${ }^{11}$ Individual wage records are then linked across quarters to create individual work histories. The firm identifier on the UI records is used to link to information on the firm available in the QCEW data, which contain information on the industry and location of the firm. A limited list of worker demographics is available; namely, sex, and date of birth.

From the LEHD data we construct a panel of linked employer-employee observations, pooling the wage histories from five large states: California, North Carolina, Oregon, Washington, and Wisconsin. ${ }^{12}$ From these pooled data we create a sample of workers with at least three years of job tenure in their main job in one of four reference quarters-1999:2, 2001:2, 2005:2, and 2009:2-that span a variety of macroeconomic conditions. For simplicity, much of our analysis focuses on reference quarter 2005:2, but we also show some results for the other reference quarters. We include in our sample both male and female workers, age 25-55, in the reference quarter. Although our sample comprises workers from five states, we track their earnings outcomes on a national basis. That is, for a worker who separates from one of our five states, we use all available national LEHD data to track earnings and employment outcomes.

We limit our sample to workers who remain employed or become re-employed within eight quarters of separation in the reference quarter. We divide this sample into three categories: stayers, job changers, and recalls. We define "stayers" as workers who are continually employed with the same employer for at least the three quarters after the reference quarter. We define "job changers"

\footnotetext{
${ }^{10}$ Data quality issues produce a small number of large outlier observations in the earnings data. We identify outliers by comparing quarterly earnings records to the median earnings value observed over the sample for each individual and winsorize these outliers at the $95^{\text {th }}$ percentile. This approach is more appealing than winsorizing by earnings levels, since it does not incorrectly adjust the earnings of high-wage workers. See Appendix for a detailed description of the winsorization methodology.

${ }^{11}$ Our data do not identify occupations or job titles. We use the terms "firm" and "employer" interchangeably throughout the paper.

${ }^{12}$ We narrow the sample to these five states in part to reduce the size of the analysis as well as to have the longest possible time series, as the availability of LEHD data for a particular year varies by state. Approximately 10 states have data available in the early 1990s.
} 
as workers who separate from their employer in the reference quarter and become re-employed with a new employer within eight quarters. We define "recalls" as workers who separate from their employer in the reference quarter but return to this same employer. Note that given the nature of our data, we can only identify recalls if the worker experiences a full quarter of nonemployment before rejoining the firm. ${ }^{13}$ Recalls that do not experience a full quarter of nonemployment are, perforce, categorized as stayers. Our analysis excludes workers who do not fall within one of the three categories. Specifically, we exclude workers who do not separate in the reference quarter but separate in one of the subsequent three quarters and workers who separate in the reference quarter but remain in nonemployment for more than eight quarters.

We further categorize workers by whether they are employed at a distressed firm in the reference quarter. We define a "distressed firm" as one that experiences a 30 percent or larger decline in employment in the year ending in the quarter subsequent to the separation. ${ }^{14}$ This is similar to the definition of "distressed firm" used in JLS. ${ }^{15}$ However, in order to facilitate comparisons between separators and stayers from like firms, we do not include separators in the reference quarter from closed firms in our sample. Sensitivity analysis shows that retaining the separators from closed firms does not substantially change our results, partly because separators from closed firms are a small proportion of separators. ${ }^{16}$ Although some of the "distressed separators" may have been quits or firings for cause, the overwhelming majority are likely separations that would not have occurred in the absence of the displacement event (Davis, Faberman, and Haltiwanger, 2006 and 2012).

\section{Tracking Separations and Re-employment in Administrative Data}

As discussed above, our goal is to trace the job and earnings paths of workers following job separations that yield a job change. We build on earlier work (Bjelland et al., 2011) on employer-to-employer flows that was restricted to job changes that occurred within the quarter of

\footnotetext{
${ }^{13}$ Attempts to use variation in quarter earnings to identify likely short temporary layoffs have proven unsuccessful.

${ }^{14}$ Because this categorization works less well for smaller firms, for all analysis where separations are broken out by the growth rate of the separating employer, we restrict our analysis to firms with at least 50 employees.

${ }^{15}$ We do not include in the sample apparent employment separations that occur in the administrative data due to firm ID changes or mergers/acquisitions. We use the pattern of worker flows to identify separations and accessions due to such events and suppress the flows that result.

${ }^{16}$ In the quarterly data, for a closing firm the final quarter of activity has less relevance than in annual data because closings occur in stages. We also think that potential linkage issues may underlie any residual large last quarter apparent closings even with our use of worker flows to abstract from such issues. In any event, our results are robust to the inclusion of such closings.
} 
job separation. This earlier work found that, on average, 30 percent of main job separations were directly to another job. To generalize the implications of employer-to-employer flows for labor market dynamics, here we also study transitions to new jobs that include a spell of nonemployment. As evidence from the displaced worker literature suggests, the ability to retain - as well as findnew employment is important in the adjustment from a job separation. ${ }^{17}$

We categorize worker flows by the duration of the jobless spell following a separation in the reference quarter. Since quarterly wage data do not provide exact start and end dates for jobs, the duration of joblessness must be inferred from the pattern of quarterly earnings in the administrative data. An example is illustrative; Example 1 below provides a sample of a fictional wage record for a worker John Doe.

Example 1: Fictional UI Earnings History

\begin{tabular}{|l|l|l|l|l|l|l|l|l|}
\hline & Firm & Y1:Q1 & Y1:Q2 & Y1:Q3 & Y1:Q4 & Y2:Q1 & Y2:Q2 & Y2:Q3 \\
\hline John Doe & A & $\$ 6000$ & $\$ 6000$ & $\$ 3000$ & & & & \\
\hline John Doe & B & & & $\$ 4000$ & $\$ 7000$ & & & \\
\hline John Doe & C & & & & & $\$ 3000$ & & \\
\hline John Doe & D & & & & & & & $\$ 4000$ \\
\hline
\end{tabular}

Employer-to-employer flows that occur within the same quarter are the shortest transitions to new employment from a job separation we can identify in the data. In Example 1, John Doe experiences such a flow from A to B in the third quarter of the first year. There may be a short nonemployment spell associated with such a flow. ${ }^{18}$ If separations and accessions were uniformly distributed throughout the quarter, the implied average nonemployment spell is five to six weeks long. However, the average spell may, in fact, be shorter: The wage patterns during these transition quarters suggest a period of overlapping paychecks associated with these flows, with the sum of quarterly earnings across all employers higher during the quarter of transition than in surrounding quarters. This suggests a relatively seamless transition between jobs. When the accession to a new job occurs in the next adjacent quarter after the job separation, the worker is much more likely

\footnotetext{
${ }^{17}$ Both this paper and our earlier paper (Bjelland et al., 2011) were instrumental in the development of the Census Bureau's Job-to-Job Flows statistics. This paper uses an early prototype of the Job-to-Job Flows microdata to identify moves across firms. Similar to our findings here, job-to-job moves with a spell of nonemployment between jobs have lower earnings growth in the public use data, available here: https://lehd.ces.census.gov/data/\#j2j.

${ }^{18}$ Haltiwanger et al. (2018a) use the individual earnings data to refine the methodology for identifying job-to-job flows. They show that the patterns of job-to-job flows are largely robust to using this more refined methodology compared to the within and within/adjacent quarter approaches. All of these approaches yield the pattern that job-tojob flows move workers up the firm wage ladder (defined using average earnings of workers).
} 
to experience a short spell of joblessness - about three months, on average, again assuming a uniform distribution of separations and accessions in each quarter. In the example, John Doe experiences this type of job flow from employer $\mathrm{B}$ to job $\mathrm{C}$ in the fourth quarter of year one. The transition between employer $\mathrm{C}$ and $\mathrm{D}$ includes one full quarter of joblessness and we categorize the remaining flows by the number of full quarters of joblessness. ${ }^{19}$

\section{Descriptive Statistics}

The main findings of the paper are previewed in Figure 1, which plots the average quarterly earnings for stayers and job changers by firm distress and duration of nonemployment. Panels (a) and (b) present the results separately for workers from distressed and non-distressed employers, respectively. Each line represents the average earnings for a group of workers defined by the duration of nonemployment. We have divided durations into six categories, being those reemployed at a new job:

1. In the same quarter as separation ("within");

2. In the quarter adjacent to the quarter of separation ("adjacent");

3. After one full quarter of nonemployment ("one");

4. After two quarters of nonemployment ("two");

5. After three quarters of nonemployment ("three");

6. After four to eight quarters of nonemployment (" $\geq$ four").

The post-separation earnings dynamics look strikingly similar for job changers from nondistressed firms, which is the first indication that firm health is not predictive of earnings losses for job changers. In contrast, post-separation earnings losses are strongly related to the duration of the nonemployment spell, with longer periods of nonemployment being associated with greater and more persistent losses.

Tables 1 and 2 describe the workers in the sample in more detail. Table 1 presents descriptive statistics for reference quarter 2005:2. The results show that relative to stayers, job changers are younger and less likely to be employed at a large firm, and that distressed separators are older than non-distressed separators but are younger than stayers. The industry that contributed

\footnotetext{
${ }^{19}$ It is important to note that a worker for whom we observe a full quarter of nonemployment most likely also did not work the entire quarter of his job separation or job accession. If we again assume uniform distributions of separations and accessions, the average worker experiencing a job flow with one full quarter of nonemployment observed experienced a six-month nonemployment spell.
} 
the largest share of distressed separators is manufacturing, with 21 percent of distressed separators coming from that sector. Table 2 presents the sample size, with 250,000 and 18,000 workers separating from non-distressed and distressed employers, respectively. The table also shows that separators from distressed employers are less likely to be recalled but no more likely than other separators to fail to find employment within eight quarters of separation. The last five columns illustrate that, conditional on changing jobs, separators from distressed and non-distressed employers spend similar amounts of time in nonemployment. Importantly, among job changers, distressed separators are no more likely to experience substantial periods of nonemployment than are non-distressed separators.

\section{Earnings Outcomes Following Separation}

The summary statistics in Figure 1 suggest a strong relationship between nonemployment and subsequent earnings losses but a weak relationship between these losses and the health of the firm. This section formalizes these findings and explores them in more detail. We start by estimating fairly standard models of earnings losses, which demonstrate that, on average, all job changers tend to experience large and persistent earnings losses regardless of whether they were employed at a distressed or a non-distressed firm. We then show that periods of nonemployment after separation are strongly predictive of subsequent earnings outcomes.

\section{V.A. "Standard" Estimation in the JLS Tradition}

As a starting point, we estimate the effect of separations that yield a job change using the distributed lag model that has become the standard in the literature since the publication of JLS. A standard representation of that model is:

$$
\text { (1) } y_{i t}=\propto_{i}+\gamma_{t}+X_{i t} \beta+\sum_{k \geq-12} S_{i t}^{k} \delta_{k}+u_{i t}
$$

where $\mathrm{y}$ is the quarterly earnings of worker $\mathrm{i}$ in quarter $\mathrm{t}, \alpha$ is an individual fixed effect, $\gamma$ is a quarter fixed effect, $\mathrm{X}$ are time-varying individual characteristics, $S_{i t}^{k}$ is an indicator equal to one if individual $\mathrm{i}$ separated $\mathrm{k}$ quarters ago as of quarter $\mathrm{t}$, and $\mathrm{u}$ is a regression residual, which is clustered at the level of the employer in the reference quarter. As in JLS, the vector X contains the interactions between sex, age, and age squared. We estimate this equation with ordinary least squares (OLS). ${ }^{20}$

\footnotetext{
${ }^{20} \mathrm{We}$ include analysis of individual specific time trends in section VII.A below.
} 
We estimate this specification on a sample defined by specific reference quarters, initially 2005:2. In turn, we consider alternative reference quarters: 1999:Q2, 2001:Q2, 2005:Q2, and 2009:Q2. Thus, for a given reference quarter, calendar time $\mathrm{t}$ and time-since-reference-quarter $\mathrm{k}$ move in lock step. To make this clear and to facilitate expanded specifications below, we rewrite equation (1) as:

$$
\text { (2) } y_{i t}=\propto_{i}+X_{i t} \beta+\sum_{k \geq-23} A_{i t}^{k} \gamma^{k}+\sum_{k \geq-12} S_{i t}^{k} \delta^{k}+u_{i t}
$$

where $A_{i t}^{k}$ is an indicator for the reference quarter being k quarters ago as of quarter $\mathrm{t}^{21}$ Note that with a single reference quarter, $\mathrm{A} \gamma$ in equation (2) serves the function served by the time fixed effects $\gamma$ in equation (1), and we have been explicit about the date range of the estimation before separators are distinguished from stayers. ${ }^{22}$ Focusing on specific reference quarters facilitates quantifying how our main results differ over time and, in particular, at different points in the business cycle.

As in the main regressions in JLS, we estimate this equation separately for the sample of distressed separators (what JLS called the "mass layoff sample") and the sample of non-distressed separators ("non-mass layoff sample"). In each case the comparison group of stayers includes stayers from all types of firms, both distressed and non-distressed, while excluding the other types of job changers. In both cases, recalls are not included in the sample. We estimate the specification on a balanced sample that includes quarterly earnings records (including quarters with zero earnings) from 24 quarters before and after the reference quarters.

Figure 2 depicts the estimates from equation (2) for the 2005:2 reference quarter and plots the estimates of $\delta^{k}$ relative to the reference quarter. Panels (a) and (b) present earnings losses (relative to all stayers) for distressed and non-distressed separators, respectively. Panel (a) replicates the standard finding that separators from distressed firms experience large reductions in earnings that persist for years. We find an initial drop of $\$ 5,150$ in quarterly earnings, and even six years after the separation, these workers earn around $\$ 2,000$ less per quarter. A comparison of the results in panels (a) and (b) reveals that the earnings patterns for separators from non-distressed

\footnotetext{
${ }^{21}$ The summation of A begins earlier than the summation for $\mathrm{S}$ to allow identification of individual fixed effects in estimation with a single reference quarter.

${ }^{22}$ While the data include observations up to 24 quarters prior to the reference quarter, we follow JLS and estimate the effect of a separation starting 12 quarters before the reference quarter. Thus, the estimated effect of the separation is relative to the earnings differences (conditional on the other covariates in the model) between separators and stayers prior to 12 quarters before the reference quarter.
} 
firms are both qualitatively and quantitatively similar. We find no indication that earnings losses are larger for distressed separators (i.e., displaced workers, as defined by firm contraction) than for other separators.

Our finding of a similarity in the earnings patterns for distressed and non-distressed separators stands in contrast with JLS, who found that non-distressed separators suffer insignificant losses in earnings after several (e.g., five or six) years. Given the very similar nature of our specifications with JLS, we think the most likely explanation for the differences between our results for non-distressed separators and those in JLS are due to the differences in time and place of our data. ${ }^{23}$ In particular, JLS's sample involves separations that take place in Pennsylvania in the period 1980-1986 (with pre-separation data that begin in 1974). Our sample (including results for the additional reference quarters reported below) involves separations that take place in California, North Carolina, Oregon, Washington, and Wisconsin in the period 1999-2009 (with pre-separation data that begin in 1993).

A comparison to two other studies similarly using administrative data on earnings suggests that time is an important factor. Von Wachter, Song, and Manchester (2009) use national data for separations in 1980-1986, a period intentionally similar to that in JLS. Although they do not estimate the formal model on non-distressed separators, in simple averages, they, like JLS, find that the earnings of non-distressed separators fully recover the ground lost to stayers after 5-8 years. In contrast, Couch and Placzek (2010) use data from Connecticut for separations in 19992004, a period that overlaps ours. They find, like us, that non-distressed separators suffer substantial earnings losses after six years. However, although they find little difference between distressed and non-distressed separators through two years, by six years the losses of nondistressed separators have fallen to one-half of distressed separators', suggesting a role for place as well as time. ${ }^{24}$

Further investigation into time and place effects would be of interest but we think that the early 1980s are arguably distinct given the massive restructuring of key manufacturing industries over

\footnotetext{
23 There are a number of small differences in sample and specifications between the analysis reported here and JLS beyond time and place. We have investigated these differences (see online appendix) and have found them not to be important.

24 Importantly, the results from Couch and Placzek (2010) also depart from JLS in finding that non-distressed separators exhibit persistent earnings losses even after six years. In this respect, their results on persistent earnings losses for non-distressed separators are between those of JLS and our results. Both of these studies use a single state. Our results use multiple states and reference periods.
} 
that time period. As Davis, Haltiwanger, and Schuh (1996) highlight, the steel industry experienced an enormous surge in job destruction in the early 1980s with integrated mills disappearing from the United States in a relatively short time period. More than half a million steel jobs at integrated mills were destroyed in the 1982-1983 period alone largely through plant closings. Our combined broader coverage of states and time periods including the Great Recession suggests our findings are less driven by this interesting but distinct period in the early 1980s.

\section{V.B. Comparison to Stayers in Same Firm Growth Category}

The regression in equation (2) implicitly compares both distressed and non-distressed separators to all stayers, regardless of whether those stayers work for distressed or non-distressed firms. Figures 4 and 5 of JLS and Section 6.1 of Jacobson, LaLonde, and Sullivan (1993b) instead distinguish stayers by type of firm. As noted in Jacobson, LaLonde, and Sullivan (1993b), this can be interpreted as estimating the effects of separation itself as opposed to the effects of the firmside conditions that contributed to the separation.

Therefore, in a further step toward our main specification, we, too, distinguish between stayers at distressed and non-distressed firms. Specifically, we estimate the following equation:

$$
\text { (3) } y_{i t}=\propto_{i}+X_{i t} \beta+\sum_{d=0}^{1} \sum_{k \geq-23} A_{i t}^{k, d} \theta^{k, d}+\sum_{d=0}^{1} \sum_{k \geq-12} S_{i t}^{k, d} \delta^{k, d}+u_{i t}
$$

where $\mathrm{d}=1$ for distressed firms and $\mathrm{d}=0$ for non-distressed firms. $A_{i t}^{k, 0}\left(A_{i t}^{k, 1}\right)$ is an indicator equal to one if the reference quarter is $\mathrm{k}$ quarters after $\mathrm{t}$ and the individual is employed at a non-distressed (distressed) employer in the reference quarter and $S_{i t}^{k, 0}\left(S_{i t}^{k, 1}\right)$ is an indicator equal to one if $A_{i t}^{k, 0}$ $\left(A_{i t}^{k, 1}\right)$ is equal to one and the individual i is a separator. In contrast to our previous specification, we estimate this equation on a pooled sample that contains both separators and stayers from distressed and non-distressed employers. As before, recalls are not included in the sample, and the sample is a balanced panel that includes all earnings records from 24 quarters before and after the reference quarter.

The estimated earnings losses for the 2005:2 sample are depicted in Figure 3. The results lead to a similar conclusion: There do not appear to be large differences in the earnings consequences of separations from distressed versus non-distressed firms. If anything, we find that separators from distressed firms experience smaller losses. Compared to the estimates from equation (2), the long-term earnings losses are slightly smaller for separators from distressed firms. 
This is likely because stayers at distressed firms tend to experience slower earnings growth. Results for non-distressed separators are similar to the estimates from equation (2), which is to be expected given that workers at distressed employers make up a small share of total stayers.

\section{V.C. Earnings Consequences and Nonemployment Spells}

A main contribution of our study is to investigate the role of jobless duration in explaining the post-separation earnings patterns, allowing outcomes to vary for direct job-to-job moves vs. those with longer jobless spells. To do this, we expand upon equation (3) and estimate the following equation (which is our main specification):

$$
\text { (4) } \begin{aligned}
y_{i t}= & \propto_{i}+X_{i t} \beta+\sum_{d=0}^{1} \sum_{k \geq-23} A_{i t}^{k, d} \theta^{k, d}+\sum_{d=0}^{1} \sum_{0>k \geq-12} S_{i t}^{k, d} \delta^{k, d} \\
& +\sum_{N=0}^{5} \sum_{d=0}^{1} \sum_{k \geq \max \{N-1,0\}} S_{i t}^{k, d, N} \delta^{k, d, N}+u_{i t}
\end{aligned}
$$

where $S_{i t}^{k, d, N}$ is an indicator equal to one if $A_{i t}^{k, d}$ is equal to one and i is a separator that had a duration of nonemployment equal to $\mathrm{N}$, where $\mathrm{N}$ is defined (as in Section IV) as re-employed at a new job:

$\mathrm{N}=0$ : In the same quarter as separation ("within");

$\mathrm{N}=1$ : In the quarter adjacent to the quarter of separation ("adjacent");

$\mathrm{N}=2$ : After one full quarter of nonemployment ("one");

$\mathrm{N}=3$ : After two quarters of nonemployment ("two");

$\mathrm{N}=4$ : After three quarters of nonemployment ("three");

$\mathrm{N}=5$ : After four to eight quarters of nonemployment (" $\geq$ four").

As in equation (3), we estimate this equation on a sample that includes all job changers and all stayers (we still exclude recalls from the sample). We do not allow for the pre-separation effects to differ by the subsequent duration of nonemployment. ${ }^{25}$ The sample includes earnings records from 24 quarters before and after the reference quarters. ${ }^{26}$

The estimates from equation (4) are presented in Figure 4, where panels (a) and (b) present results for distressed $\left(\delta^{k, 1, N}\right)$ and non-distressed $\left(\delta^{k, 0, N}\right)$ separators, respectively. A very clear

\footnotetext{
25 As above, pre-separation effects can differ between separators and stayers. However, the duration of nonemployment conditional on separating is a function of the worker, not the firm of separation, so the same logic does not apply.

${ }^{26}$ For separators that experience at least one full quarter of nonemployment we drop from the sample the quarter following the separation up through one quarter prior to when they find a new job because these quarters have zero earnings by construction. As before, quarters of zero earnings after finding a new job are included in the sample.
} 
pattern emerges from the figure: The duration of time spent in nonemployment prior to finding a new job is strongly related to the magnitude and persistence of earnings losses, while these losses are not strongly related to the health of the firm (distressed versus non-distressed). ${ }^{27}$ We find an immediate earnings gain but not much persistent earnings change for individuals who find reemployment within the quarter of separation, whether from distressed or non-distressed firms. ${ }^{28}$ For individuals who find re-employment in the adjacent quarter the loss in quarterly earnings six years after separation exceeds $\$ 1,000$ and the loss exceeds $\$ 3,000$ for those who experience four or more quarters of nonemployment. The figure illustrates a clear monotonic relationship in which longer periods of nonemployment are associated with larger, more persistent earnings losses.

It is important to highlight that earnings variation induced by changes in hours or fraction of weeks worked within a quarter are included in these statistics. This approach is consistent with the literature and implies that some of the persistent earnings losses observed for job changers with spells of joblessness may reflect such hours and employment variation. That is, the large and persistent earnings losses after six years reported above for those experience four or more quarters of nonemployment may reflect subsequent spells of joblessness (although we restrict our analysis to workers with positive earnings eight quarters after separating). Examining implications for earnings fluctuations more closely linked to wages is challenging with these administrative data. However, we include an exercise below in section V.F that takes an important step in that direction by focusing on the full quarter earnings implications of changing jobs.

\section{V.D. Robustness to Variation in Macro Conditions}

We find similar patterns in reference periods that span a range of macroeconomic conditions. In addition to the reference quarter 2005:2 which we feature, we estimate equation (4) on three additional samples defined by the reference quarters 1999:2 (a tight labor market), 2001:2 (a relatively mild recession) and 2009:2 (a severe recession). The results are presented in Figure

\footnotetext{
${ }^{27}$ In interpreting our results, it is important to highlight that our findings are about spells of nonemployment, not only unemployment. Using the matched monthly CPS data for the years 2004 and 2006 (bracketing one of our reference quarters in 2005), we find, as others have, that the rate of workers moving from employment to out of the labor force at high frequencies is quite high even for sub-groups with seemingly strong labor force attachment. In particular, even among employed men ages 35-44, a highly attached group, about 15 percent of separators each month leave the labor force. Of these, 38 percent said that they want a job. This suggests that movements out of the labor force may be an important element of the nonemployment we observe even among prime-age males.

${ }^{28}$ Section V.F relates our findings on earnings gains from job-to-job flows to the recent job mobility literature.
} 
5 and illustrate the robustness of our main results across these various macroeconomic conditions, even comparing a boom year like 1999 to the Global Financial Crisis year of 2009.

\section{V.E. Quantifying the Importance of Nonemployment}

The results in Figures 3 and 4 indicate that the duration of time spent in nonemployment is predictive of post-separation earnings outcomes, whereas the health of the employer is not. In order to further quantify this statement, we estimate two restricted versions of equation (4) and compare their explanatory power to that of the unrestricted model. In the most restrictive model, we do not allow for differential effects of separations by either employer type or duration of nonemployment. Formally, we require that $\delta^{k, d, N}=\delta^{k}$. In the intermediate model, we allow the effect of separation to differ by the health of the firm but not by duration of nonemployment. Formally, we require that $\delta^{k, d, N}=\delta^{k, d}$. To quantify the explanatory power of each model, we implement the fixed effects estimation using a within estimator, which allows us to interpret the resulting R-squared as the proportion of within individual variation explained by the model. ${ }^{29}$ All specifications are estimated on the same sample described for the estimation of equation (4).

The results indicate that the most restrictive model, in which the effects of separations do not vary by employer type or nonemployment duration, explains 3.7 percent of the within individual variation in earnings (that is, the R-square is 0.037). As expected, we find that allowing the effect of separation to vary by employer type, but not by nonemployment duration, adds virtually no explanatory power to the model, increasing the R-squared by only 0.005 percent. In contrast, the unrestricted version in equation (4), which allows the effects of separation to vary by nonemployment duration, explains about 6.9 percent more of the within individual variation than the most restrictive model. ${ }^{30}$ While the overall increase in explanatory power may be considered modest, clearly the differential effects of separation by nonemployment duration are far more important than the differential effects by firm health.

\section{V.F. Earnings Changes Throughout the Distribution}

The literature has documented a large dispersion in earnings outcomes for displaced workers. Because of the many parameters involved, examining dispersion using equation (4)

\footnotetext{
${ }^{29}$ To implement the within estimator we de-mean all variables in the model by individual level means (averages are calculated across time and within individuals) and run OLS on transformed variables.

${ }^{30}$ Note that both increases $(0.005$ and 6.9 percent) are percentage increases (not percentage point increases), calculated off of the R-squared of the most restrictive model, which is 0.037 .
} 
would be difficult in practice. Instead, we estimate the change in log earnings from before to after the job separation, in particular from four quarters before the reference quarter (e.g., 2004:Q2 for reference quarter 2005:Q2) to the first full quarter of earnings after re-employment. A distinction of this approach relative to equation (4) is that we focus on full quarter earnings changes so that the inferences are more closely linked to changes in wages.

For each subsample of job changers based on the duration of nonemployment $\mathrm{N}$ (as defined above), we estimate,

$$
\text { (5) } \Delta y_{i}=\alpha+\beta X_{i}+\gamma Z_{j(i)}+\sum_{g=2}^{4} A_{i}^{g} \lambda^{g}+\sum_{g=1}^{4} S_{i}^{g} \delta^{g}+u_{i}
$$

where $\Delta y_{i}$ is the change in log real earnings; $X_{i}$ is a vector of worker characteristics that include age, sex, and tenure as of the reference quarter; $Z_{j(i)}$ is a vector of characteristics of the firm of employment as of the reference quarter that includes size, state, and the growth rate of the industry within the state; $A_{i}^{g}$ is an indicator equal to one if person i worked at a firm in growth category g; $S_{i}^{g}$ is a dummy variable equal to 1 if $A_{i}^{g}$ equals one and the worker separated in the reference quarter; and $u_{i t}$ is a regression residual, where standard errors are clustered at the level of the employer in the reference quarter. This first difference specification implies that we are abstracting from fixed unobserved heterogeneity that affects the level of earnings. The vectors $\mathrm{X}$ and $\mathrm{Z}$ control for differences in earnings trajectories along the dimensions that we can measure in our data. We restrict the sample to individuals who had changes in $\log$ earnings between -1.2 and 0.8 , to eliminate outliers. To ease the computational burden, we select a subsample of stayers who are observably similar to the separators using propensity score matching. In the interests of space, we show the results of these regressions for only the 2005:Q2 reference quarter.

Because we estimate the earnings change for a single interval instead of across the range of quarters following separation, the number of parameters is greatly reduced relative to equation (4). We take advantage of this to expand the number of categories of firm growth to:

$\mathrm{g}=1$ : Rapidly shrinking: $-100 \%<$ change in employment $<-30 \%$;

$\mathrm{g}=2$ : Slowly shrinking: $-30 \% \leq$ change in employment $<0$;

$\mathrm{g}=3$ : Slowly growing: $0 \leq$ change in employment $<+30 \%$;

$\mathrm{g}=4$ : Rapidly growing: change in employment $\geq+30 \%$.

We start by estimating equation (5) via OLS and the results are presented in panel (a) of Figure 6. The figure plots the predicted average earnings changes for separators from each growth 
category of firm relative to stayers, evaluated at the means of the other covariates. Our main findings are robust to this alternative estimation strategy that uses more detailed firm growth categories. $^{31}$ Specifically, average earnings losses are similar for distressed and non-distressed separators, while the losses vary substantially by duration of nonemployment.

To see if the key patterns in Figure 6 (a) hold throughout the distribution of earnings changes, we estimate quantile regressions of the same form as equation (5) for the $10^{\text {th }}, 25^{\text {th }}, 50^{\text {th }}$, $75^{\text {th }}$, and $90^{\text {th }}$ quantiles. The predicted earnings changes at each quantile (again, evaluated at the means of the other covariates) are shown in panels (b) through (f) of Figure 6 . At the $10^{\text {th }}, 25^{\text {th }}$, $50^{\text {th }}$, and $75^{\text {th }}$ percentiles, there is no clear pattern of distressed separators faring worse than other separators, while earnings changes fall markedly as the observed nonemployment duration increases. At the $90^{\text {th }}$ percentile we continue to find no role for the firm's growth rate in predicting earnings changes. But while longer periods of nonemployment are generally associated with worse outcomes, the relationship is weaker and noisier relative to the other results.

As can be seen in Figures 6 (d-f), job changers that transition immediately (within quarter job-to-job flow) fare well at $50^{\text {th }}$ percentile and above regardless of whether displaced or not. The OLS results imply that the average worker also experiences a modest earnings increase relative to stayers following a job change within the same quarter. At the $50^{\text {th }}$ percentile the earnings gain is less than $10 \log$ points but rises to above $20 \log$ points at the $75^{\text {th }}$ percentile and to about $40 \log$ points at the $90^{\text {th }}$ percentile. These patterns are robust to the growth rate of the origin firm.

Job changers that don't transition immediately on average fare poorly especially if the spell of nonemployment is two quarters or more. At the mean, a job changer with four-to-seven quarters of nonemployment has an earnings decline relative to stayers that exceeds 20 percent regardless of the growth rate of the origin of the firm. For the lower percentiles, the earning losses are even greater. At the $25^{\text {th }}$ percentile, the earnings loss for an analogous job changer exceeds forty percent regardless of the growth rate of the origin firm.

There are subtle differences between the interpretations of Figures 4 and 6, but the broad implications are the same. Importantly, both figures suggest that job changers with longer spells of joblessness fare relatively worse regardless of the growth rate of the origin firm. However, the

\footnotetext{
${ }^{31} \mathrm{We}$ also estimated variants of equations (2), (3), and (4) that use finer categories of firms' employment growth. In unreported results, we find our conclusions are unaffected: With the finer categories as well, earnings losses and nonemployment durations among job changers are similar across firm growth categories and vary greatly by nonemployment duration. Because of the large number of parameters, we do not show these results.
} 
two figures convey somewhat different information. Figure 6 conveys information about the difference in pay between the new and old job and suggests that workers who make a within quarter job transition move to higher paying jobs, which is especially true at the $50^{\text {th }}$ percentile and above. In contrast, workers who experience a spell of nonemployment move to lower paying jobs with the decline in pay increasing in the duration of the nonemployment spell. Figure 4 conveys information about total earnings after the separation (which may include periods of nonemployment). Workers who make a within quarter transitions experience an increase in earnings immediately after the separation but the gains are not persistent. ${ }^{32}$ Workers who experience nonemployment experience persistent earnings losses with the losses increasing in the duration of the nonemployment spell.

Comparing Figure 6 to estimates of earnings gains from job-to-job flows from Haltiwanger et al. (2018a, b) highlights an important feature of the current analysis. Both the current and these prior papers find earnings gains from job-to-job flows using the LEHD data. However, the magnitudes are not directly comparable since the current paper imposes additional restrictions on the sample to be consistent with the displaced worker literature. Specifically, in the current paper we focus on workers with at least three years of tenure at their main job prior to the reference quarter of the separation, are 25-55 years old, and are re-employed within eight quarters. The first two of these restrictions implies we are likely missing the rapid moves up the job ladder for younger workers and the associated earnings gains highlighted by Haltiwanger, Hyatt and McEntarfer (2018b). Still in spite of these restrictions, we find earnings gains from direct job-tojob flows in Figure 6 for workers on average and at the $50^{\text {th }}$ percentile and above. The sample restrictions also offer a likely explanation for why we find little persistent differences in earnings (and not earnings gains for movers) between within quarter job changers and stayers in Figure 4.

\section{Nonemployment Following Job Separation}

Our estimates so far indicate that job changers from distressed firms suffer no larger earnings losses, on average, than do job changers from other firms, both overall and conditional on the length of nonemployment between separation and accession to a new job. While these results would seem to imply that distressed separators are no more likely to experience a substantial

\footnotetext{
${ }^{32}$ Spells of nonemployment offer one possible explanation for the lack of persistent earnings gains for within-quarter job changers in Figure 4. By definition these workers are all employed at their new job in the quarter after the separation. However, new jobs tend to be less stable and thus these workers are relatively more likely to experience separations and spells of nonemployment in subsequent quarters.
} 
period of joblessness following a separation, this section directly examines this relationship. In addition, we explore the role of recalls, which up until this point have been excluded from our analysis.

We estimate a competing-risks hazard model in which the two risks are becoming reemployed at a new employer and becoming re-employed at the same employer from which one separated (recall). We assume that recalls dominate new jobs, in the sense that a worker recalled in a particular quarter is not in the risk set for taking a new job in that quarter, while a worker taking a new job in a particular quarter is in the risk set for being recalled in that quarter. We use the same categories of nonemployment duration as we have throughout, and the finer categories of firm employment growth as in Section V. We model the probability of becoming re-employed at a new job at each duration of nonemployment, conditional on not already being re-employed, as

\section{(6) logit(new job in $t \mid$ not reemployed before $t$ and not recalled in $t)_{i}$}

$$
=\alpha_{t}+\beta_{t} X_{i}+\gamma_{t} Z_{j(i)}+\lambda_{t} g_{j(i)}+\mu_{i t}
$$

and the probability of recall analogously as

$$
\begin{gathered}
\text { (7) logit(recalled in } t \mid \text { not reemployed before } t)_{i} \\
=\alpha_{t}^{\prime}+\beta_{t}^{\prime} X_{i}+\gamma^{\prime}{ }_{t} Z_{j(i)}+\lambda_{t} g_{j(i)}+\mu_{i t}^{\prime}
\end{gathered}
$$

As above, $X_{i}$ is a vector of worker characteristics that includes age, sex, and tenure at the separating firm; $Z_{i}$ is a vector of characteristics of the separating firm, namely, size, state, and the growth rate of the industry within the state; and $g_{j(i)}$ is an indicator variable for the category of firm growth (rapidly shrinking, slowly shrinking, slowly growing, and rapidly growing).

From these two models we then obtain predicted probabilities for each of the four growth rate categories evaluated at the mean of all other covariates. We use these predicted probabilities to construct the cumulative distribution function (CDF) of time until re-employment, that is, the probability of exiting nonemployment by a given quarter after separation - the complement of the survivor function implied by equation (6). See Appendix for details.

The results are displayed in Figure 7. Panel (a) displays the CDF for new jobs (conditional on no recall) and illustrates that the duration of time spent in nonemployment is unrelated to the growth of the firm from which the worker separated. Panel (b) shows analogous results for recalls. Here we see markedly different patterns for distressed separators and other separators. As would be expected, individuals who separate from rapidly shrinking firms are far less likely to be recalled. 
The finding of greater likelihood of a spell of nonemployment for distressed separators is driven by recalls.

It might at first glance be surprising that distressed separators experience similar durations of nonemployment conditional on never being recalled. If individuals choose to separate from their employer, we might think that many would have another job already lined up and thus be less likely to experience nonemployment. However, there are several possible reasons for why distressed separators might find employment at a new job at as fast a rate as non-distressed separators. One is that workers from distressed firms may anticipate the separation and begin searching for another job ahead of time. ${ }^{33}$ Another is that the workers separating from distressed firms know that recall to their former employer is unlikely, and so they search more intensely for new jobs rather than wait to be recalled. This explanation would be broadly consistent with Katz and Meyer (1990) and Fallick and Ryu (2007). A third possibility is that the patterns in Figure 7 may reflect a smaller "lemon's effect" for separators from distressed firms: Potential employers might have greater confidence in the quality of the pool of workers separating from a distressed firm, increasing the rate and quality of job offers relative to those of non-distressed separators. ${ }^{34}$

To close this section, it is useful to discuss our findings in light of the empirical literature regarding distressed separators, layoffs, and unemployment. Two key findings from that literature are important in this context. First, the proportion of separations that are job losses-layoffs rather than quits-increases sharply with the rate at which a firm contracts (Davis, Faberman, and Haltiwanger, 2006 and 2012). Second, job losers are more likely to become unemployed and to experience more unemployment than job leavers (e.g., Elsby, Hobijn, and Sahin, 2010). These two observations suggest that separators from distressed firms should experience more unemployment, both in incidence and duration, than do separators from non-distressed firms.

Our findings are not inconsistent with these observations, for two main reasons. First, our findings about distressed and non-distressed separators having similar patterns of nonemployment are conditional on not being recalled. Not only are non-distressed separators more likely to be

\footnotetext{
${ }^{33}$ The Worker Adjustment and Retraining Notification (WARN) Act requires most employers in the US with more than 100 employees to give 60-day advance notice of a plant closure or mass layoff. Research into the impact of advance notice on post-displacement earnings and employment has generally found that notice reduces the number of displaced individuals who experienced a jobless spell during the event (e.g., Addison and Blackburn, 1997).

${ }^{34}$ For recent discussions, see Carrington and Fallick (2017, p.697); and Flaaen, Shapiro, and Sorkin (2019, p.212). Recent work by Abraham et al. (2019) suggests that unobserved heterogeneity does not account for observed duration dependence, but it still might be important in distinguishing between separators.
} 
recalled conditional on at least one quarter of nonemployment, but, as discussed above, in our data we cannot identify separations that end in recall within the quarter of separation or in the adjacent quarter. Thus, recalls associated with short durations of nonemployment are not captured in our sample. Such recalls after short durations of nonemployment are likely higher at growing firms. ${ }^{35}$ Second, as noted previously, we measure nonemployment rather than unemployment.

\section{Why the Relationship between Jobless Duration and Earnings Losses?}

Why is the duration of time spent in nonemployment so strongly related to post-separation earnings losses? A number of possible economic explanations have important - and potentially conflicting - implications for how we understand the experiences of displaced workers and of the more general process through which earnings are determined. One may divide explanations into three rough and potentially overlapping classes. First, differences in time spent in nonemployment may reflect heterogeneity across workers not yet taken into account that is correlated with earnings, and in particular heterogeneity in degree of labor market attachment or other economic circumstances. Second, spending an extended period of time in nonemployment might produce earnings losses. This could happen because of a depreciation of human capital (or lack of human capital gained), because spending time in nonemployment sends a bad signal to potential employers, or because separation with nonemployment causes a worker to fall to a lower rung of the job ladder. Third, the duration of joblessness prior to finding a new job may be a symptom of other factors that lead to earnings losses. For example, the propensity to move up or down the firm earnings ladder may be related to whether the worker makes a direct job-to-job transition. Alternatively, workers whose local economies have suffered decline might have a harder time finding a new job and might have to settle for lower wages upon re-employment. In this section we discuss several possible explanations about which we can offer some evidence.

\section{VII.A. Worker Heterogeneity}

As in previous research in the JLS tradition, heterogeneity across workers in our sample in their degree of labor force attachment is limited by the restriction that every separated worker in

\footnotetext{
35 Another possibility is that the finding in the literature that job losers experience more unemployment is an artifact of respondents to household surveys like the Current Population Survey failing to report short or casual jobs (Abraham, et al., 2013). We investigated this possibility by deleting new jobs with particularly low quarterly earnings or those that lasted only one quarter. We also tried deleting jobs with temporary help firms or professional employer organizations (NAICS 5623) and adding separations that occurred in the other three quarters of the year (in case one quarter is prone to more short seasonal jobs than another). None of these alterations significantly changed our results.
} 
our sample has at least three years of tenure prior to separating and is observed to be re-employed within eight quarters of separation. However, it is possible that significant heterogeneity along this dimension remains. Less strongly attached workers may be both slower to become reemployed and more likely to choose to accept jobs with reduced hours or lower wages.

Arguing against this possibility is the quantitative as well as qualitative similarity in postseparation earnings between separators from distressed and non-distressed firms in the results already presented, both conditional and not conditional on the duration of time spent in nonemployment, combined with the finding that firm distress is not predictive of the amount of time separators spend in nonemployment (absent recall). If heterogeneity in labor market attachment were a major factor amongst this restricted group of job changers, we would not expect to find these similarities, since separations from non-distressed employers are more likely to result from decisions made by the worker.

Further evidence is provided by the similarity across widely varying macroeconomic conditions that we noted above. Because one would expect the mix of labor force attachment among job changers to vary with the cyclical state of the labor market, the similarity in results across the reference years argues against worker heterogeneity in attachment as an explanation for our results.

To explore this possibility further, we consider additional controls for unobserved heterogeneity by adding linear individual-specific time trends to our main specification (4). The results are presented in Figure $8 .{ }^{36}$ Relative to our main results, (i) the earnings losses of distressed separators are slightly smaller and (ii) the strength of the association between duration of nonemployment and earnings losses is somewhat weaker. However, qualitatively the relationship between duration of nonemployment and earnings losses is robust to the inclusion of the individual-level trend, as we continue to find that average earnings losses are monotonically increasing in the duration of nonemployment. These results suggest that workers who spend more time in nonemployment were not simply on flatter earnings trajectories prior to separating.

Next, we re-estimate equation (4) within a number of subgroups of workers that are likely to be more homogeneous in labor market attachment than in the full sample. Specifically, we reestimate equation (4) on the following subsamples:

\footnotetext{
${ }^{36} \mathrm{We}$ omit confidence intervals from the figure since computational constraints prevent us from clustering standard errors.
} 
a. Workers re-employed within four quarters of separation;

b. Workers with at least five years of tenure before separation;

c. Omitting jobs with particularly low quarterly earnings (average annual earnings in three years prior to reference quarter do not exceed $\$ 10,000)$;

d. Omitting jobs in the temporary help and related industries (NAICS 5623).

e. Men ages 35-44;

f. Women ages $25-34 ;^{37}$

g. Women who gave birth during the 2005 reference quarter or the adjacent quarters; ${ }^{38}$

These results are summarized in Table 3 which presents the average earnings losses for each group measured in the 20 quarters after re-entry into the labor market; more formally, the average values of $\delta^{k, d, N}$, for $\mathrm{k}=[\max \{\mathrm{N}-1,0\}, \max \{\mathrm{N}-1,0\}+19]$. Our main result is robust within every group: Earnings of separators are similar across the distressed and non-distressed firms, while nonemployment duration is a key factor associated with earnings losses.

The results present in Table 3 and Figure 5 focus on earnings, but our main results related to the duration of nonemployment are similarly robust. In unreported results, we estimate the duration specifications presented in Figures 7 within each of the samples defined by the other reference periods and the characteristics of the workers. Within each sample, we find that distressed and non-distressed separators have similar durations to re-employment at a new job, but distressed separators are much less likely to be recalled.

Taken together, these results lead us to conclude that it is unlikely that worker heterogeneity from either observed or unobserved factors accounts for our results.

\section{VII.B. Depreciation of Human Capital}

Many models of earnings suggest that human capital depreciates in an absolute sense from nonuse during periods of nonemployment. While depreciation of human capital would predict larger earnings losses for workers who spend more time in nonemployment, two features of our results argue against this explanation. The first is the steep increase in earnings losses between workers with within-quarter versus adjacent-quarter transitions, and again between workers with adjacent-quarter transitions and one-quarter of nonemployment. It seems unlikely that human

\footnotetext{
37 That is, women in the post-schooling age groups with the highest fertility rates.

${ }^{38}$ We use the ages of own-children in the 2010 decennial census to identify these women. To increase power, we retain all stayers in the sample, but limit the sample of separators to new mothers.
} 
capital would depreciate so quickly. The second is the long persistence of these losses following re-employment. Human capital depreciation from a short jobless spell should be regained long before that point. Thus, it seems unlikely that depreciation in human capital explains our results, although we do caution that we do not have direct evidence that would rule out this mechanism.

\section{VII.C. Falling Down the Job Ladder}

Job ladders emerge naturally as a feature of models with on-the-job search in the presence of search and matching frictions in the labor market (e.g., Moscarini and Postel-Vinay, 2013). Workers move up the job ladder via job-to-job flows for firms ranked by productivity and by firmspecific earnings premia correlated with such productivity differentials. Firms at the top of the job ladder primarily hire from lower ranked firms while firms at the bottom primarily hire from nonemployment. Haltiwanger et al. (2018a,b and 2021) provide empirical support for such predictions showing that job-to-job flows tend to move workers up the job ladder for firms ranked by firm-level pay premia, firm-level productivity, or average firm earnings. The findings using firm-level pay premia are especially relevant in the current context since such premia abstract from worker heterogeneity.

Building on these findings, we ask whether movements up or down the job ladder (measured in a variety of ways) is related to the duration of the spell of nonemployment following a separation. To start, we decompose earnings using an AKM decomposition using the LEHD data. ${ }^{39}$ With the AKM firm fixed effects, we use the specification described in equation (5) to estimate the relationship between firm distress, duration of nonemployment, and job mobility to firms with higher (or lower) AKM firm-fixed effects. Specifically, we estimate a version of equation (5) where we replace the change in earnings on the left-hand side with the difference between the AKM firm fixed effect of the destination and origin firm. Given the nature of this outcome variable, these regressions include only separators.

The results presented in panel (a) of Figure 9 indicate that transitions to firms with a lower firm fixed effect are strongly related to the duration of time spent in nonemployment but unrelated to the health of the firm. In other words, the qualitative patterns in changes in individual earnings are mirrored in changes in the firm fixed effect. Moreover, a comparison of panel (a) of Figure 6

\footnotetext{
39 The firm fixed effects are estimated on an annual sample that contain average quarterly earnings of the main employer between 2002 and 2009. In addition to individual and firm fixed effects, the empirical model also controls for year fixed effects and the interaction between education, sex, and a third-order polynomial in age. Following Card et al. (2018) age is normalized to 40. See Appendix for details.
} 
and panel (a) of Figure 9 reveals that the point estimates are of the same sign and order of magnitude. On average, workers who make a within-quarter transition move to firms with a fixed effect that is approximately $2 \log$ points higher, whereas workers who spend four or more quarters in nonemployment move to firms with fixed effects that are at least 9 log points lower. These estimates are roughly half the size of the estimated effects on the change in individual log earnings. Thus, these estimates suggest that workers who spend significant time in nonemployment suffer earnings losses, in large part, because they move to lower-paying firms upon re-employment. Our results imply that being hired by a higher paying firm becomes increasingly less likely for workers as they get back on the job ladder following an extended spell of joblessness.

We consider alternatives to the AKM firm premia for ranking firms in panel (b) and (c) of Figure 9. The estimates in panel (b) and (c) of Figure 9 indicate the duration of time spent in nonemployment is also strongly related to movements down the job ladder defined by average earnings and productivity, respectively. ${ }^{40}$ The patterns for the productivity job ladder are noisier, which may be due to the fact that our measure of productivity is only a valid measure of productivity within industries. For this purpose, we use a within industry relative ranking of firms of productivity as in Haltiwanger et. al. (2021). See Appendix for details.

Jarosch (2015), Krolikowski (2017), and Jung and Kuhn (2019) develop models in which job ladders play an important role in generating persistent earnings losses following job losses and which offer a partial, but incomplete, explanation of our results. In these models, firms that occupy higher rungs of the job ladder offer jobs that pay more and are more stable (i.e., the jobs have a lower probability of exogenously ending with an involuntary separation). An involuntary separation is costly because the subsequent job is likely to be lower on the ladder (since it takes time to find a high-quality job), yielding lower pay immediately, and also persistently by increasing the frequency of subsequent separations. In Jarosch (2015) and Jung and Kuhn (2019), the periods of nonemployment also reduce human capital relative to employed workers, which further persistently reduces relative earnings. Thus, these models are consistent with our findings in the sense that they predict that earnings losses will be associated with movements down the job ladder for those experiencing a separation into nonemployment.

\footnotetext{
${ }^{40}$ The firm-level measures of average earnings and productivity are measured between 2002 and 2009. Productivity data are measured as the log revenue per worker deviated from the four-digit industry average (see Haltiwanger et al. 2021). Percentile ranks are calculated across the national distribution and are employment weighted.
} 
However, none of the existing models offer a clear explanation for why the duration of nonemployment is strongly related to earnings losses and movements down the job ladder for separators from non-distressed and distressed firms alike. Several open questions are prompted by our findings. Are these patterns driven by the choices of the firm or the worker? Are firms that occupy higher rungs of the job ladder more likely to search for workers that are currently employed at other firms? Does the duration of nonemployment simply distinguish between workers who quit for a higher-paying job and other types of separations? If so, why are the earnings losses and time spent in nonemployment so similar between separators from distressed and non-distressed firms? Does the reservation wage of a worker decline with time spent in nonemployment? Given the strength of this relationship, a priority of future work should be to extend models of job ladders to explain why time spent in nonemployment is related to earnings losses and movements down the job ladder for all workers who change employers.

Figure 10 presents estimates based on whether the original employer had a high or low firm fixed effect (defined by above or below the sample median). Within both samples, we continue to see that longer periods of nonemployment are associated with moves further down the ladder. However, we also observe some mean reversion, as individual who initially start on a low rung of the job ladder tend to move to higher paying firms, while those that start on a high rung of the job ladder tend to move to lower paying firms.

\section{VII.D. Local Labor Demand}

Workers who separate into labor markets with little demand for their skills may struggle to find a new job quickly and may command lower earnings, generating the observed correlation between nonemployment and earnings losses. The variation across workers in our sample thus may reflect declines in demand for labor in local areas or in some workers' industries or occupations (and thus declines in the value of those workers' industry- or occupation-specific human capital). To explore this possibility, we measure the strength of the relevant local labor market by the employment growth rate in each 3-digit NAICS industry in each state, and the employment growth rate in each 3-digit Census occupation in each state, and divide them into weak and strong categories. ${ }^{41}$ We then estimate equation (4) and the duration results from

\footnotetext{
${ }^{41}$ Industry/state employment growth is measured within the LEHD and assigned to each worker by her industry in 2005:2. We categorize observations into three groups: weak, average, and strong. Occupation/state employment growth is measured between 2001 and 2002 using data from the BLS' Occupational Employment Studies program and is assigned to each worker using his occupation in the 2000 Decennial Census. Thus, for the results by occupation,
} 
equations (6) and (7) separately by the strength of the local labor market defined by industry and occupation classifications.

Table 4 presents the estimates of the earnings consequences and shows that within all subsamples, we continue to find a strong associated between earnings losses and duration of time spent in nonemployment. ${ }^{42}$ As before, we also see little difference between the earnings losses by firm distress. Figures 11 and 12 present the duration estimates for the subsamples defined by industry and occupation growth, respectively. For the results by industry, we find some evidence that individuals who separate from rapidly shrinking firms in shrinking industries take longer to find a new job. In addition, within both of the subsamples defined by occupation, workers who separate from rapidly shrinking firms take slightly longer to find a job. However, these differences are relatively modest. More importantly, there do not appear to be large differences in the duration of time spent in nonemployment across the different samples that characterize the strength of the local labor market (as opposed to firm growth). This latter result casts some doubt on the possibility that that association between earnings losses and nonemployment is driven by local labor market demand. While state may be too crude a measure of geography and the industry and occupation measures may be too broad to fully capture changes in "local" labor demand, these results suggest that declining local demand is not the primary explanation of our main findings.

\section{Conclusion}

The literature on job change is split into two strands: one focusing on displaced workers and the other on job mobility. The job mobility literature finds that workers benefit from job-tojob transitions whereas research on displaced workers finds they have large and persistent earnings losses. In this paper, we seek to bridge the gap between these two approaches, by analyzing outcomes for all attached separators, including a mass layoff sample, and stratifying separations by jobless duration between employment spells. In keeping with the displaced worker literature, our focus here is on attached job movers, and our results should be interpreted as applying to workers in a previously stable job match who change jobs, due to a mass layoff or unknown factors.

\footnotetext{
we use the sample based on the 2001 reference quarter. Given that the sample for which we can measure occupation is much smaller, we defined only weak and strong labor markets based on above and below the median employment growth rate for the occupation class within the state.

${ }^{42}$ As in Table 3, Table 4 presents the average earnings losses for each group measured in the 20 quarters after re-entry into the labor market; more formally, the average values of $\delta^{k, d, N}$, for $k=[\max \{N-1,0\}, \max \{N-1,0\}+19]$.
} 
We find that heterogeneity in outcomes for job changers is driven by jobless duration between job spells, with little additional explanatory power from the health of the origin firm (e.g. a mass layoff event). On average, attached separators experience similar earnings losses as those displaced in mass layoff events. However, direct job-to-job movers generally move to higher paying jobs and do not experience persistent earnings losses, findings that are broadly consistent with the job mobility literature. Earnings losses for job changers are specific to separators who experience joblessness, with losses increasing with the length of the jobless spell. Relatedly, we also find that separators from distressed firms experience no more nonemployment that do separators from non-distressed firms (if they are not recalled). These findings are robust to multiple empirical specifications, different controls for worker heterogeneity, and hold within narrow subcategories of workers.

We investigate several possible economic explanations for these results. Our analysis suggests a key mechanism driving earnings losses from job separations is workers falling down the job ladder. We find that job changers with significant spells of joblessness are more likely to become re-employed on a lower rung of the job ladder (defined by the firm-specific earnings premium from an AKM decomposition of earnings). Our findings suggest job ladder models may prove as useful for understanding earnings losses from job separations as they currently are for understanding earnings gains from job moves. Currently, job ladder models do not have a mechanism that explains the strong association between the duration of the joblessness spell and the quality of the job a worker accepts. Expanding job ladder models to capture this strong relationship between jobless duration and match quality should be a priority for future research.

It is worth emphasizing that, despite our finding that displaced worker outcomes are quite similar to attached job changers generally, we do not argue that the focus on displaced workers in the economics literature is misplaced. This group of workers is of interest for at least two reasons. First, they may be more likely to experience the separation as an unanticipated shock, and thus while the earnings consequences are similar to those of other separators, the welfare consequences may be different. Second, separations are more likely to be exogenous, which makes for a more straightforward interpretation of the empirical results. However, we do encourage future researchers to direct their focus on the role of jobless duration in understanding earnings losses for displaced workers as opposed to factors unique to mass layoff events. 


\section{References}

Abowd, John C. Haltiwanger, and Julia I. Lane, 2004. Integrated Longitudinal Employee-Employer Data for the United States. American Economic Review Papers and Proceedings, 94(2): 224-229. DOI: 10.1257/0002828041301812.

Abowd, J. M., Kramarz, F., \& Margolis, D. N., 1999. High wage workers and high wage firms. Econometrica, 67(2), 251333.

Abowd, John, Bryce Stephens, Lars Vilhuber, Fredrik Andersson, Kevin L. McKinney, Marc Roemer, and Simon Woodcock, 2006. "The LEHD Infrastructure Files and the Creation of the Quarterly Workforce Indicators." LEHD Technical Paper No. 2006-01.

Abraham, Katharine G., John Haltiwanger, Kristin Sandusky, and James Spletzer, 2013. "Exploring Differences in Employment Between Household and Establishment Data.” Journal of Labor Economics, 31(2): 2. DOI: $10.1086 / 669062$.

Abraham, K.G., Haltiwanger, J., Sandusky, K. and Spletzer, J.R., 2019. “The Consequences of Long-Term Unemployment: Evidence from Linked Survey and Administrative Data.” ILR Review 72(2):266-299. DOI: $10.1177 / 0019793918797624$.

Addison, John T., and McKinley L. Blackburn, 1997. “A Puzzling Aspect of the Effect of Advance Notice on Unemployment.” ILR Review 50(2): 268-288. DOI: 10.1177/001979399705000205.

Addison, John T., and Pedro Portugal, 1989. "Job Displacement, Relative Wage Changes, and Duration of Unemployment,” Journal of Labor Economics 7(3): 281-302. DOI: 10.1086/298209.

Bender, Stefan, Christian Dustmann, David Margolis, and Costas Meghir, 1999. "Worker displacement in France and Germany,” IFS Working Papers, No. W99/14, Institute for Fiscal Studies (IFS), London. DOI: 10.1920/wp.ifs. 1999.9914

Bjelland, Melissa, Bruce Fallick, John C. Haltiwanger, and Erika McEntarfer, 2011. "Employer-to-Employer Flows in the United States: Estimates Using Linked Employer-Employee Data." Journal of Business and Economic Statistics, 29(4): 493-505. DOI: 10.1198/jbes.2011.08053.

Brown, Claire, John C. Haltiwanger, and Julia I Lane, 2006. Economic Turbulence: Is a Volatile Economy Good for America? (University of Chicago Press). DOI: 10.7208/chicago/9780226076348.001.0001.

Card, David, Ana Rute Cardoso, Joerg Heining, and Patrick Kline. "Firms and labor market inequality: Evidence and some theory." Journal of Labor Economics 36, no. S1 (2018): S13-S70.

Carneiro, Anabela, and Pedro Portugal, 2006. "Earnings Losses of Displaced Workers: Evidence from a Matched Employer-Employee Data Set.” Banco de Portugal Working Paper \#14-2006.

Carrington, William J., and Bruce Fallick, 2017. “Why Do Earnings Fall with Job Displacement?” Industrial Relations 56(4), October, 688-722. DOI: 10.1111/irel.12192.

Couch, Kenneth A., and Dana W. Placzek, 2010. "Earnings Losses of Displaced Workers Revisited." American Economic Review, 100 (1): 572-89. DOI: 10.1257/aer.100.1.572.

Couch, Kenneth A., Nicholas A. Jolly, and Dana W. Placzek, 2011. "Earnings Losses of Displaced Workers and the Business Cycle: An Analysis with Administrative Data.” Economics Letters, 1111(1), April 2011, 16-19. DOI: 10.1016/j.econlet.2010.12.011.

Davis, Steven J., and Till von Wachter, 2011. "Recessions and the Costs of Job Loss." Brookings Papers on Economic Activity (Fall), 1-72. DOI: 10.1353/eca.2011.0016.

Davis, Steven J., R. Jason Faberman, and John Haltiwanger, 2006. “The Flow Approach to Labor Markets: New Evidence and Micro-Macro Links." Journal of Economic Perspectives, 20(3): 3-26. DOI: 10.1257/jep.20.3.3.

Davis, Steven J., R. Jason Faberman, and John Haltiwanger, 2012, "Labor Market Flows in the Cross Section and Over Time." Journal of Monetary Economics, 59 (1-18). DOI: 10.1016/j.jmoneco.2011.10.001.

Davis, Steven J., John C. Haltiwanger, and Scott Schuh, Job Creation and Destruction (Cambridge, MA: MIT Press, 1996).

Elsby, Michael, Bart Hobijn and Asyegul Sahin, 2010. "The Labor Market in the Great Recession." Brookings Papers on Economic Activity (Spring), pp. 1-48. DOI: 10.1353/eca.2010.0001.

Fackler, Daniel, Steffen Müller, and Jens Stegmaier. "Explaining wage losses after job displacement: Employer size and lost firm rents.” No. 32/2017. IWH Discussion Papers, 2017.

Fallick, Bruce, and Keunkwan Ryu, 2007. "The Recall and New Job Search of Laid-off Workers: A Bivariate Proportional Hazard Model with Unobserved Heterogeneity." Review of Economics and Statistics 89(2), pp. 313-323. DOI: 10.1162/rest.89.2.313.

Flaaen, Aaron, Matthew D. Shapiro, and Isaac Sorkin, 2019. "Reconsidering the Consequences of Worker Displacements: Firm versus Worker Perspective.” American Economic Review: Macroeconomics, 11(2), pp.193227. DOI: $10.1257 / \mathrm{mac} .20170162$. 
Gregory, Victoria, Guido Menzio, and David Wiczar, 2021, “The Alpha Beta Gamma of the Labor Market,” NBER Working Paper no 28663.

Haltiwanger, John, Henry Hyatt, Lisa Kahn, and Erika McEntarfer, 2018a. "Cyclical Job Ladders by Firm Size and Firm Wage.” American Economic Journal: Macroeconomics, 10(2): 52-85. DOI: 10.1257/mac.20150245.

Haltiwanger, Joh, Henry Hyatt, and Erika McEntarfer, 2018b. "Who Moves Up the Job Ladder?" Journal of Labor Economics, S301-S336.

Haltiwanger, John, Henry Hyatt, Erika McEntarfer and Matthew Staiger. 2021. “Cyclical Labor Market Flows and Productivity-Enhancing Reallocation." Unpublished.

Hijzen, Alexander, Richard Upward, and Peter W. Wright, 2010. “The Income Losses of Displaced Workers.” Journal of Human Resources, 45(1), 243-269. DOI: 10.1353/jhr.2010.0000.

Jacobson, Louis, Robert LaLonde, and Daniel Sullivan, 1993a. "Earnings Losses of Displaced Workers.” American Economic Review, vol. 83(4), pages 685-709.

Jacobson, Louis, Robert LaLonde and Daniel Sullivan, 1993b. The Costs of Worker Dislocation. Upjohn Institute Press. ISBN: 978-0-88099-143-8

Jarosch, Gregor, 2015. "Searching for Job Security and the Consequences of Job Loss", manuscript, December 2015.

Jung, Philip and Moritz Kuhn, 2019. "Earnings Losses and Labor Mobility over the Life Cycle". Journal of the European Economic Association, 17(3), pp.678-724 DOI: 10.1093/jeea/jvy014

Katz, Lawrence, and Bruce D. Meyer, 1990. "Unemployment Insurance, Recall Expectations, and Unemployment Outcomes." The Quarterly Journal of Economics, 105(4), 973-1002. DOI: 10.2307/2937881.

Krolikowski, Pawel. 2017. "Job Ladders and Earnings of Displaced Workers." American Economic Journal: Macroeconomics, 9(2): 1-31. DOI: 10.1257/mac.20140064.

Lachowska, Marta, Alexandre Mas, and Stephen A. Woodbury. 2020. “Sources of displaced workers' long-term earnings losses." American Economic Review, 110(10), pages 3231-3266.

Liu, Kai, 2019. "Wage risk and the value of job mobility in early employment careers." Journal of Labor Economics, 37(1), pp. 139-185. doi: 10.1086/698898.

Maestas, N., Mullen, K.J. and Strand, A., 2015. Does delay cause decay? The effect of administrative decision time on the labor force participation and earnings of disability applicants (No. w20840). National Bureau of Economic Research.

Moore, Brendan, and Judith Scott-Clayton. The Firm's Role in Displaced Workers' Earnings Losses. No. w26525. National Bureau of Economic Research, 2019.

Moscarini, Giuseppe, and Fabien Postel-Vinay. 2013. "Stochastic Search Equilibrium." Review of Economic Studies 80(4): 1545-1581.

Postel-Vinay, Fabien, and Jean-Marc Robin. "Equilibrium wage dispersion with worker and employer heterogeneity." Econometrica 70.6 (2002): 2295-2350.

Raposo, P., Portugal, P. and Carneiro, A., 2019. The sources of the wage losses of displaced workers: the role of the reallocation of workers into firms, matches, and job titles. Journal of Human Resources, pp.0317-8667R3.

Schmieder, J.F., von Wachter, T. and Bender, S., 2016. The effect of unemployment benefits and nonemployment durations on wages. American Economic Review, 106(3), pp.739-77.

Schmieder, J., Till von Wachter, and Joerg Heining. "The costs of job displacement over the business cycle and its sources: evidence from Germany.” 2020.

Schoeni, Robert F., and Michael Dardia, 2003. "Earnings Losses of Displaced Workers Using California Administrative Data." PSC Research Report No. 03-543, Population Studies Center, Institute for Social Research, University of Michigan, December 2003.

Topel, Robert, and Michael Ward, 1992. "Job Mobility and the Careers of Young Men," , 107(2), 439-79, May. DOI: $10.2307 / 2118478$.

Von Wachter, Till M., Elizabeth Weber Handwerker, and Andrew K.G. Hildreth, 2009. “Estimating the 'True’ Cost of Job Loss: Evidence Using Matched Data from California 1991-2000.” Center for Economic Studies Paper No. CES-WP-09-14. Suitland, MD: U.S. Census Bureau. DOI: 10.2139/ssrn.1444552.

Von Wachter, Till, Jae Song, and Joyce Manchester. 2009. "Long-Term Earnings Losses due to Mass-Layoffs During the 1982 Recession: An Analysis Using U.S. Administrative Data from 1974 to 2004”, manuscript, April 2009. 


\section{Figures}

Figure 1: Average Earnings

(a) Distressed

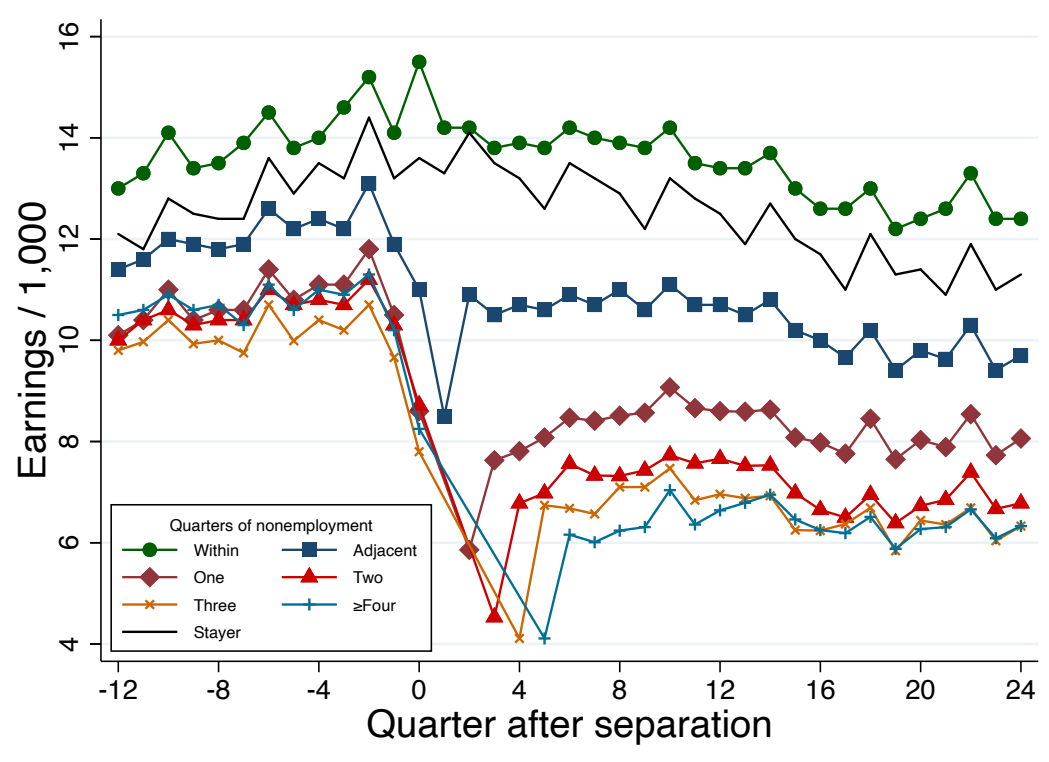

(b) Non-Distressed

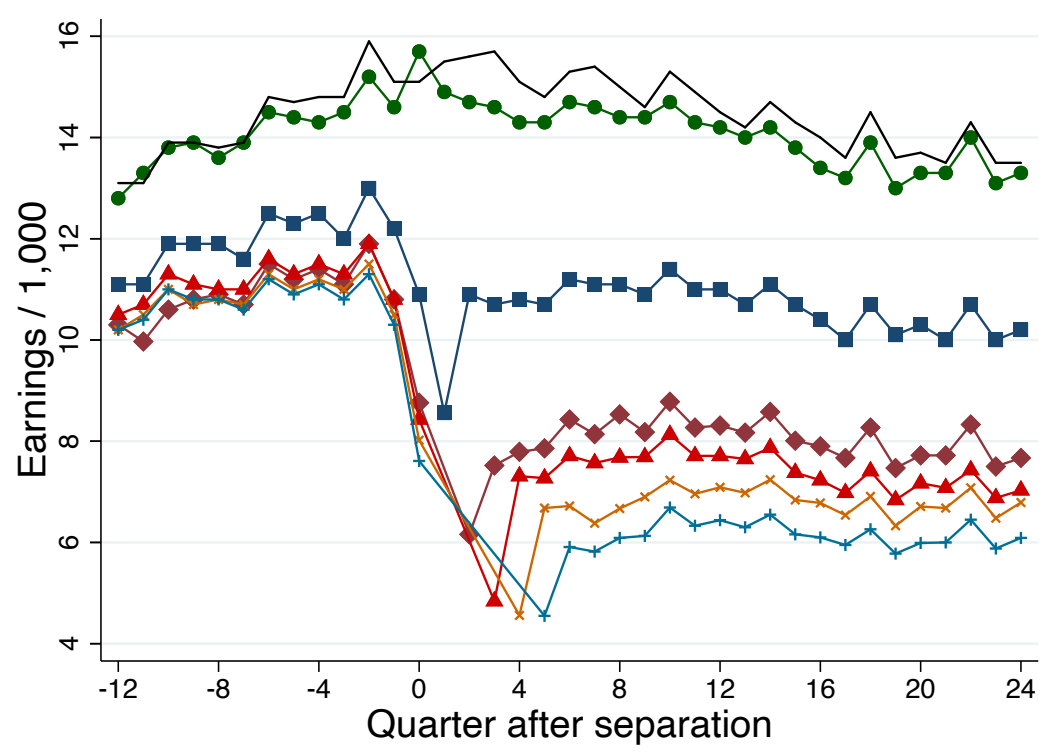

Notes: The figure presents the average earnings of workers in the three years before and six years after 2005:2. Panels (a) and (b) present results for distressed and non-distressed employers, respectively. The lines within each panel present averages for different groups of workers, including stayers and separators who spend various amounts of time in nonemployment prior to being reemployed. 
Figure 2: Effect of Separation Relative to all Stayers

(a) Distressed

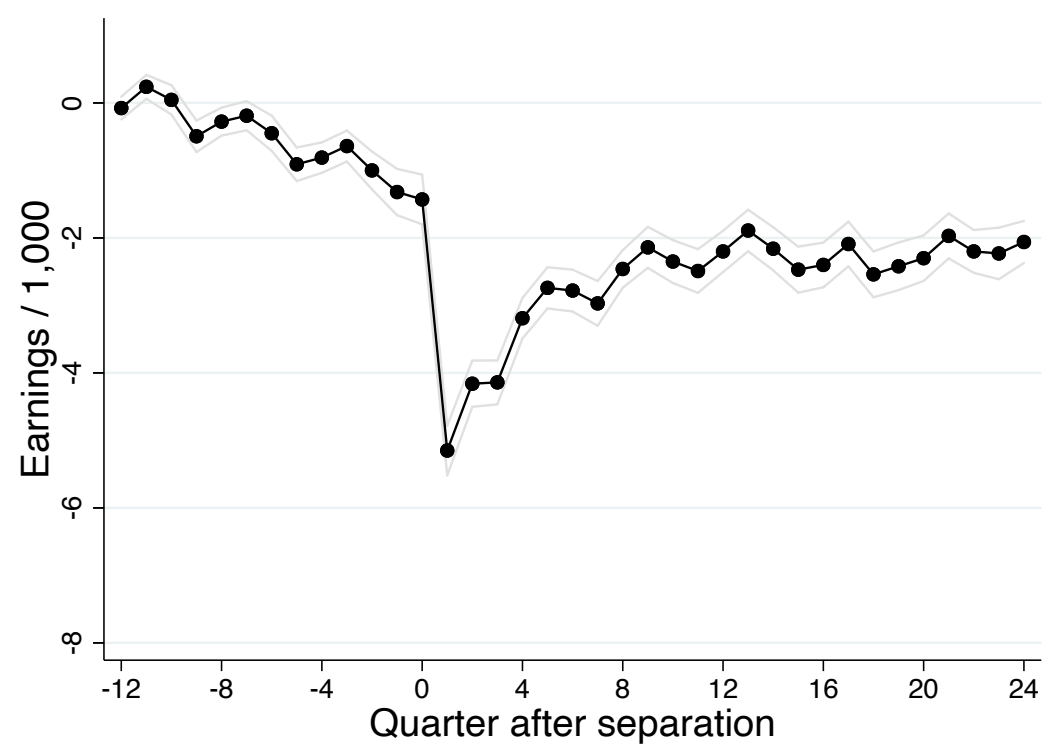

(b) Non-Distressed

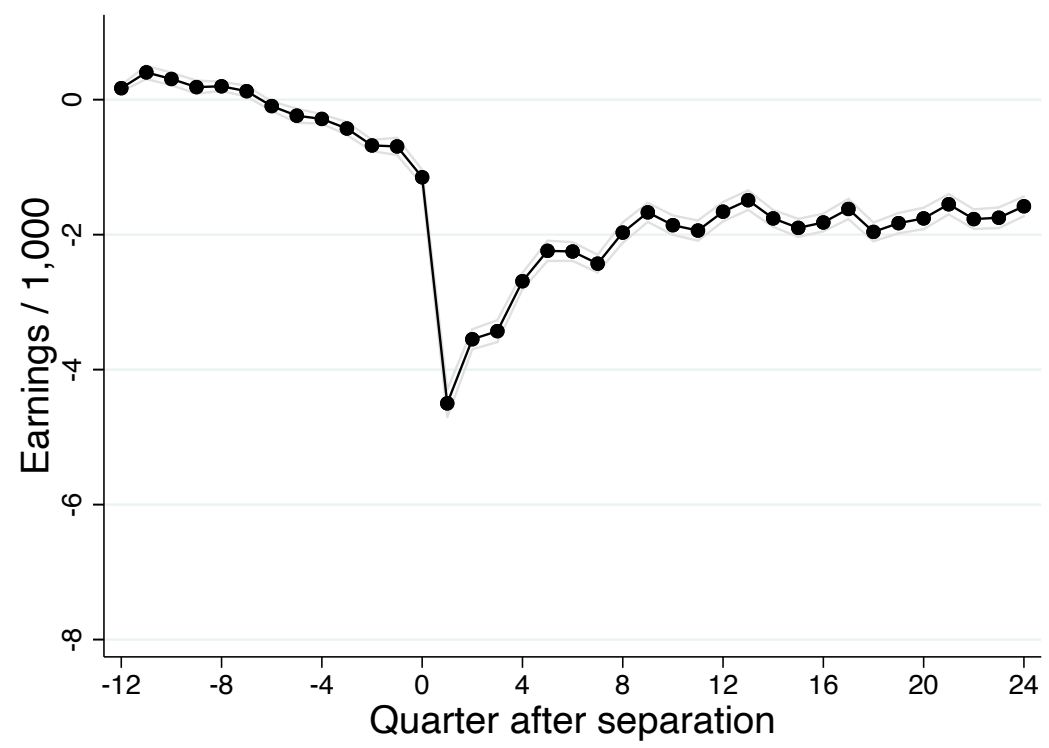

Notes: The figure presents the estimated earnings consequences of a job separation by firm health (distressed and non-distressed). Results presented in panels (a) and (b) are derived from a sample in which separators are from distressed and non-distressed firms, respectively. Stayers from all employers are included in both samples and neither sample includes recalls. The sample corresponds to reference period 2005:2. The figure displays estimates obtained from the empirical model described in equation (2). The estimates of $\delta^{k}$ are plotted against the quarter relative to displacement. Standard errors are clustered at the level of the employer in the reference quarter and the solid gray lines depict the 95 percent confidence interval around the estimates. 
Figure 3: Effect of Separation Relative to Stayers in Same Firm Growth Category

(a) Distressed

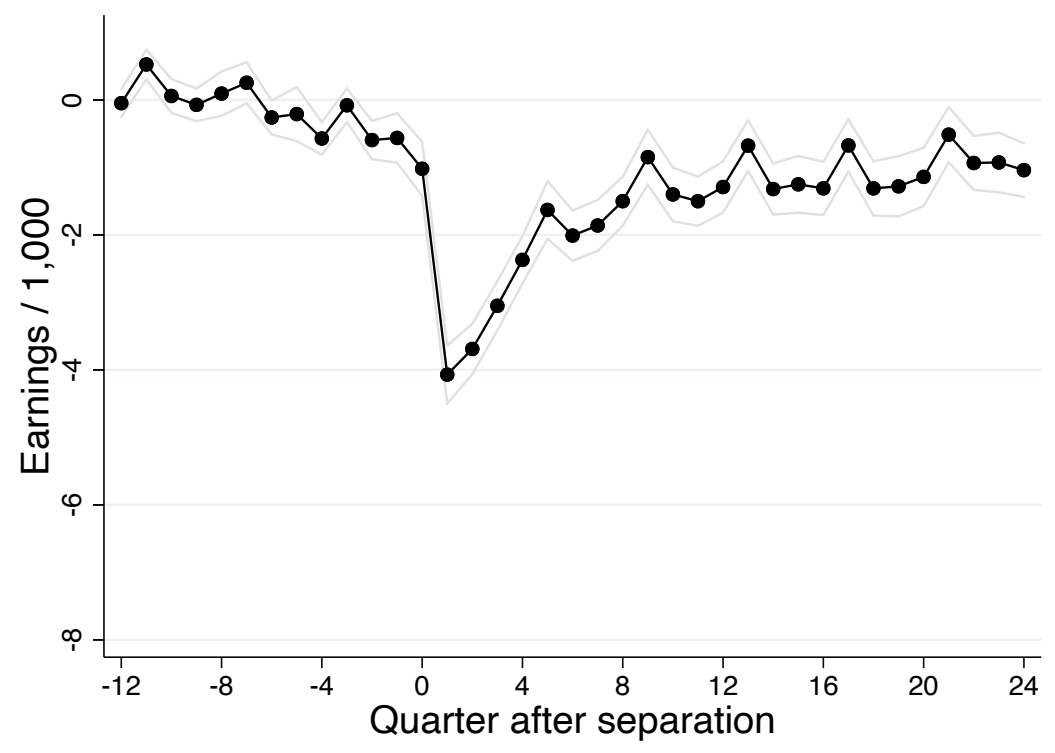

(b) Non-Distressed

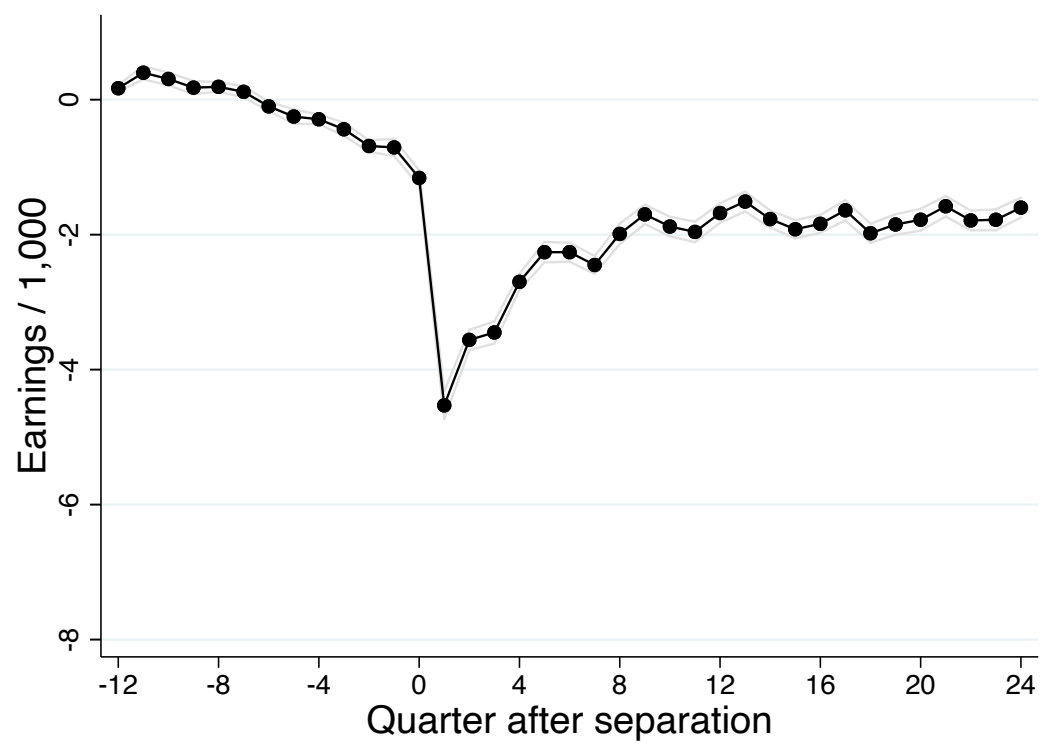

Notes: The figure presents the estimated earnings consequences of a job separation by firm health (distressed and non-distressed). The results are derived from a sample that excludes recalls but includes all other stayers and separators. The sample corresponds to reference period 2005:2. The figure displays estimates obtained from equation (3). Panels (a) and (b) plot the estimates of $\delta^{k, 1}$ and $\delta^{k, 0}$ against the quarter relative to displacement, respectively. Standard errors are clustered at the level of the employer in the reference quarter and the solid gray lines depict the 95 percent confidence interval around the estimates. 
Figure 4: Effect of Separation by Duration of Nonemployment

(a) Distressed

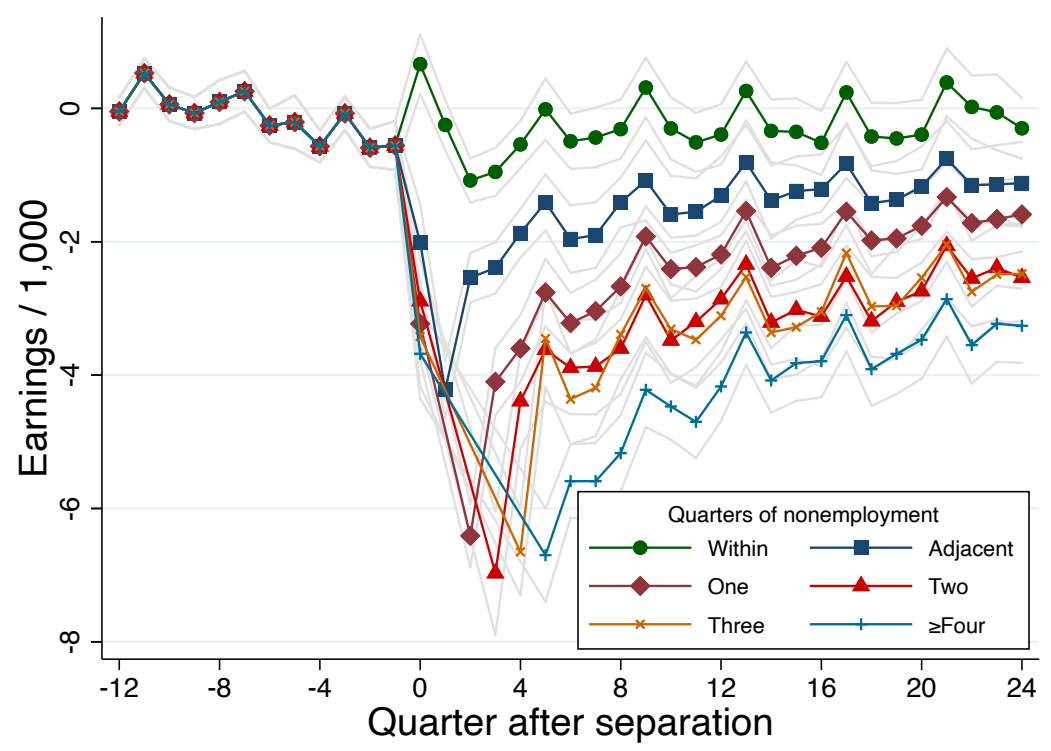

(b) Non-Distressed

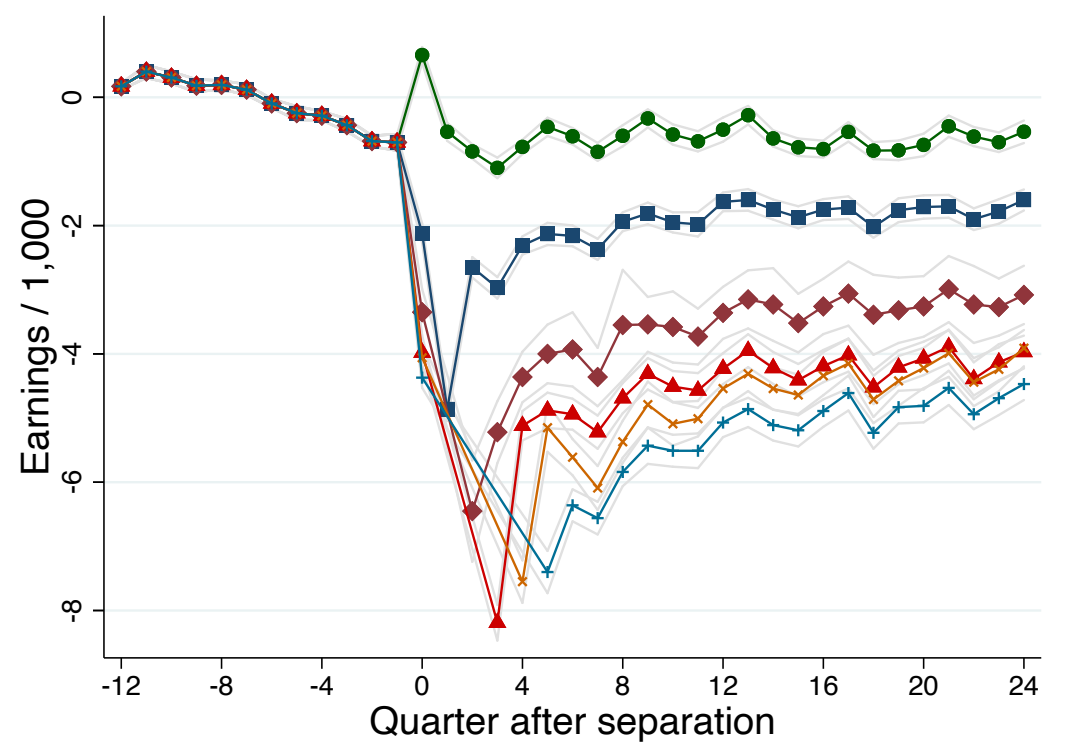

Notes: The figure presents the estimated earnings consequences of a job separation by firm health (distressed and non-distressed) and duration of nonemployment. The results are derived from a sample that excludes recalls but includes all other stayers and separators. The sample corresponds to reference period 2005:2. The figure displays estimates obtained from equation (4). Panels (a) and (b) plot $\delta^{k, 1, N}$ and $\delta^{k, 0, N}$ against the quarter relative to displacement, respectively. Standard errors are clustered at the level of the employer in the reference quarter and the solid gray lines depict the 95 percent confidence interval around the estimates. 
Figure 5: Effects of Separations in Other Reference Periods

(a) Distressed Separators in 1999

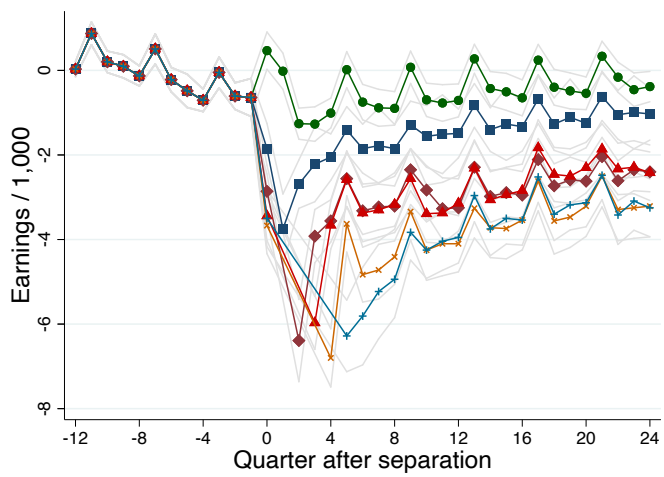

(c) Distressed Separators in 2001

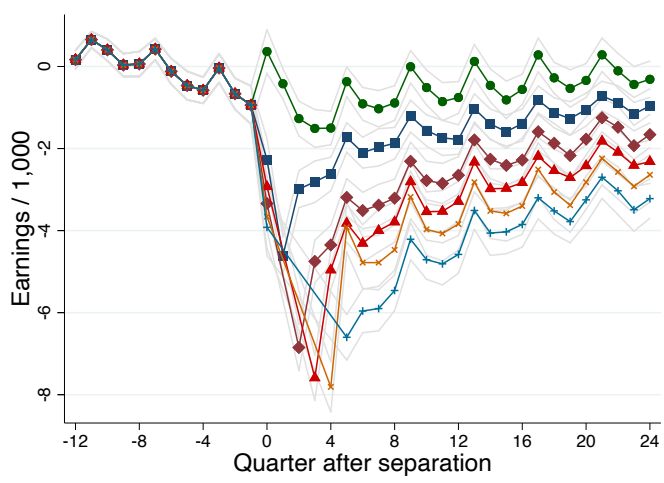

(e) Distressed Separators in 2009

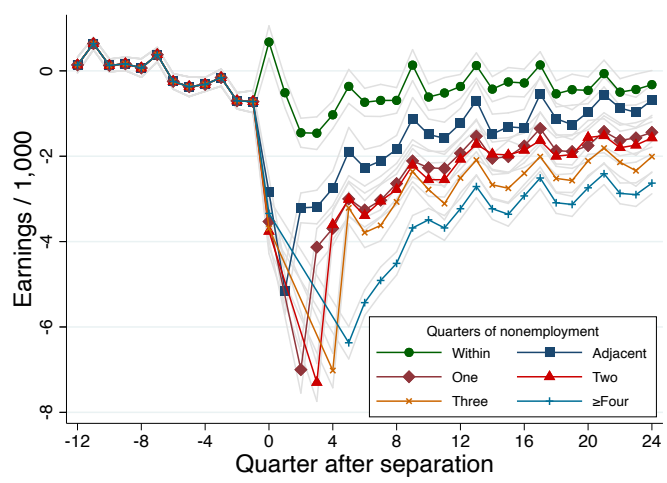

(b) Non-Distressed Separators in 1999

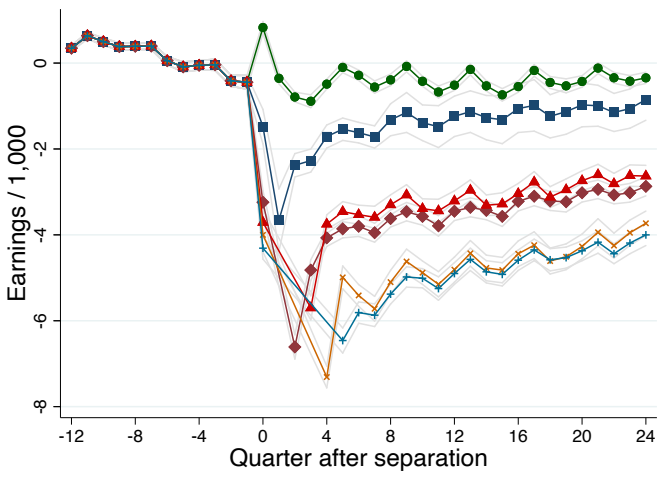

(d) Non-Distressed Separators in 2001

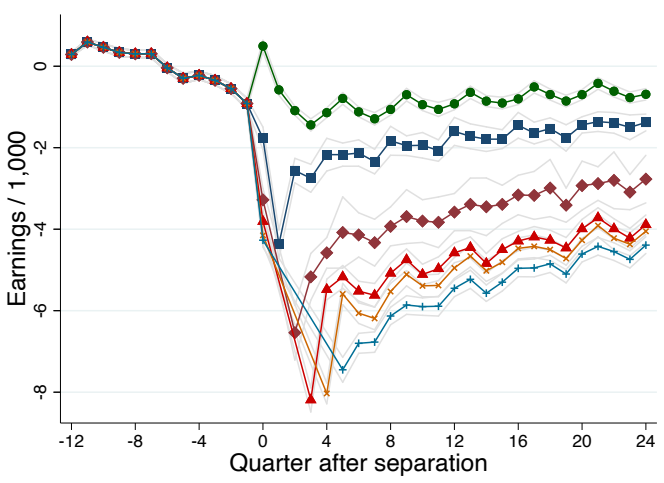

(f) Non-Distressed Separators in 2009

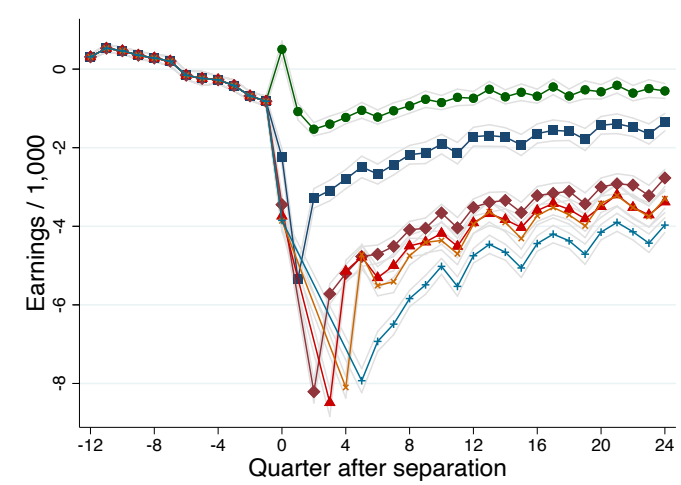

Notes: The figure presents the estimated earnings consequences of a job separation by firm health (distressed and non-distressed), duration of nonemployment, and reference period. The first, second, and third row presents estimates for reference quarters 1999:2, 2001:2, and 2009:2, respectively. All samples exclude recalls but include all other stayers and separators. The figure displays estimates obtained from equation (4). The left and right columns plot $\delta^{k, 1, N}$ and $\delta^{k, 0, N}$ against the quarter relative to displacement, respectively. Standard errors are clustered at the level of the employer in the reference quarter and the solid gray lines depict the 95 percent confidence interval around the estimates. 
Figure 6: Predicted Change in Earnings

(a) Ordinary Least Squares

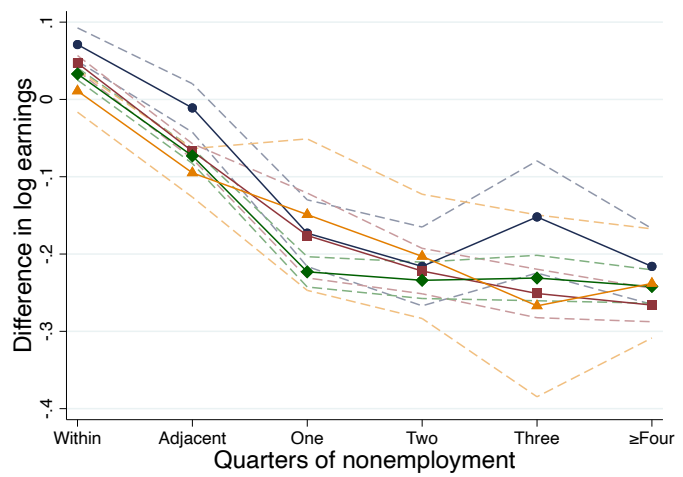

(c) 25th Quantile

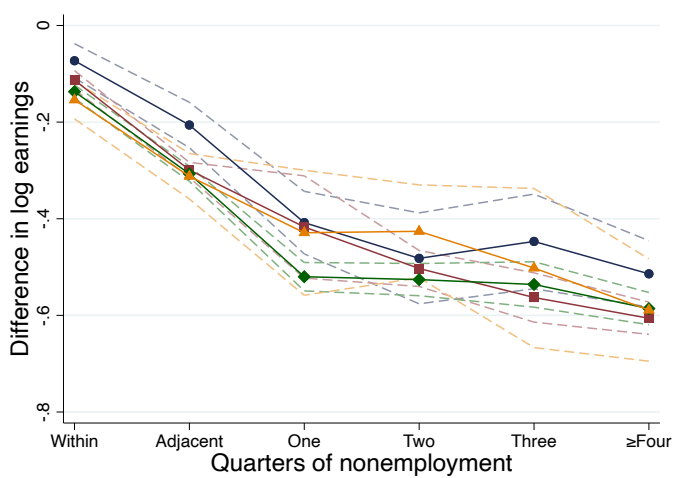

(e) 75th Quantile

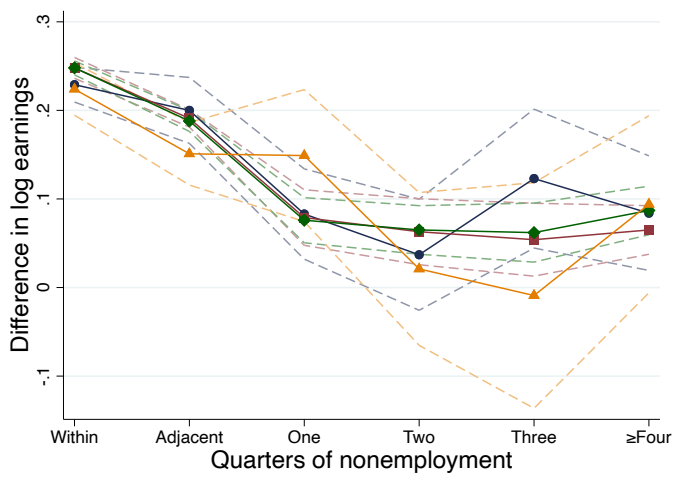

(b) 10th Quantile

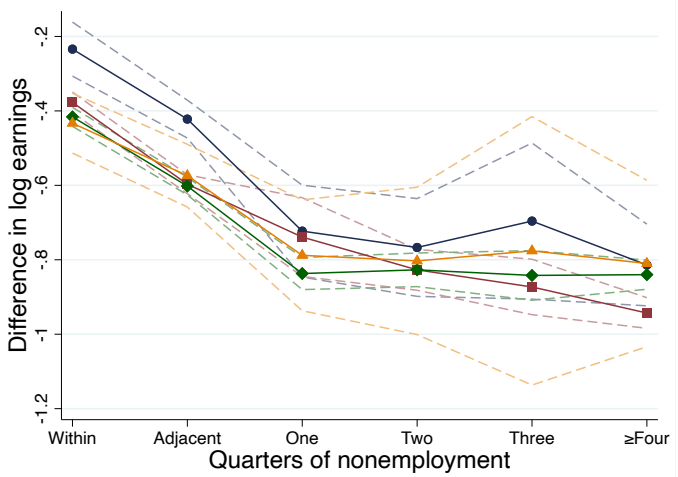

(d) 50th Quantile

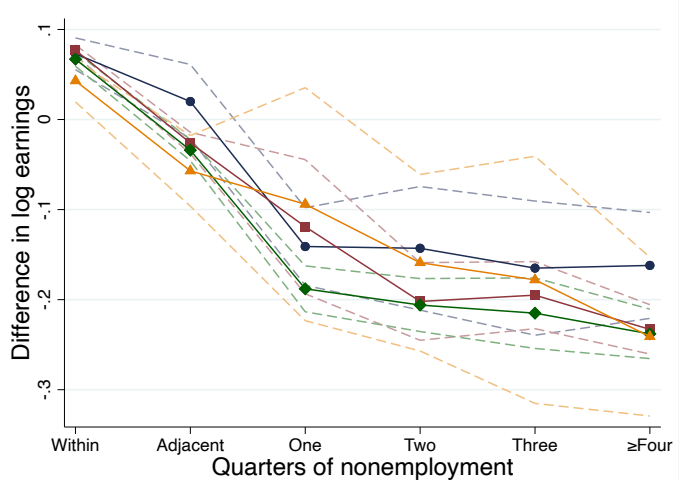

(f) 90th Quantile

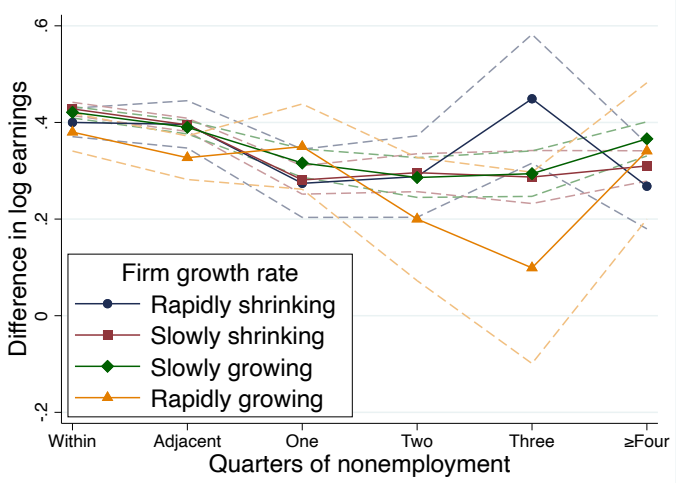

Notes: The figures present the predicted earnings penalties for separators from each growth category of firm relative to stayers, evaluated at the means of the other covariates. The estimates are obtained from equation (5). Earnings prior to separation are measured four quarters prior to separation and earnings post-separation are measured one quarter after re-employment. Panel (a) presents results from ordinary least squares (OLS) and panels (b)-(f) present results from quantile regressions, where the 10th, 25th, 50th, 75th, and 90th percentiles are reported. Within each figure, each line represents the firm growth category and the horizontal axis denotes the duration of time spent in nonemployment prior to re-employment. Standard errors are clustered at the level of the employer in the reference quarter and the dotted lines represent the 95 percent confidence interval. 
Figure 7: Duration of Nonemployment

(a) Job Changers

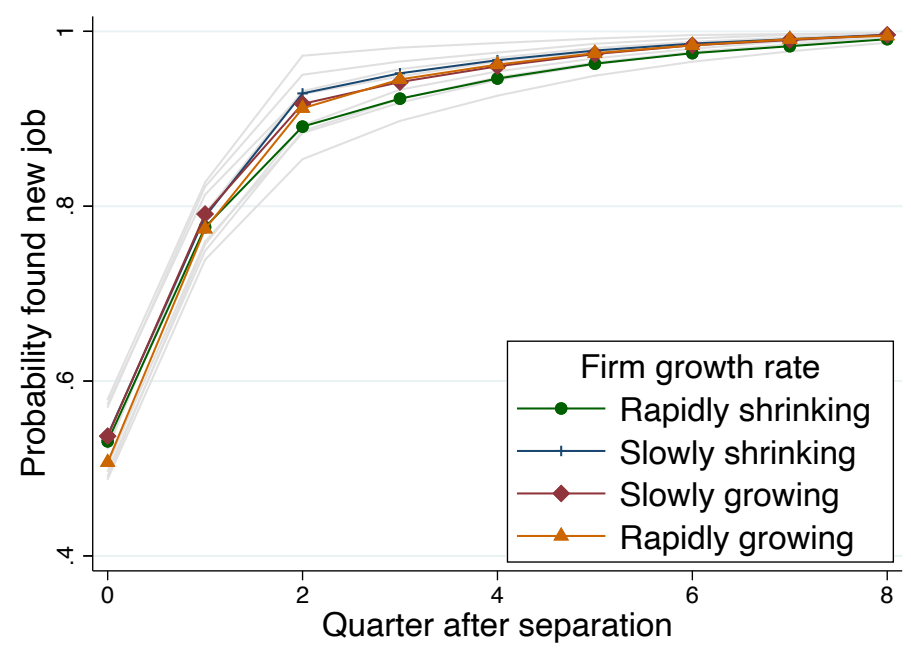

(b) Recalls

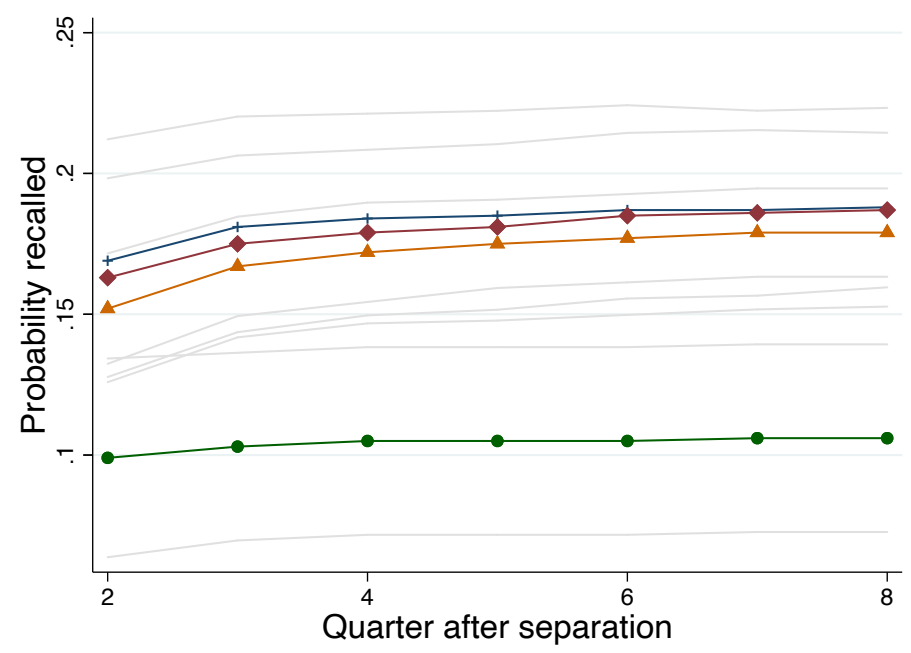

Notes: Panels (a) and (b) present the probability of exiting nonemployment by a given quarter after separation for job changers and recalls, respectively. The probability of a separator finding a new job in a given quarter after separation and the probability of a separator being recalled in a given quarter after separation are estimated by logistic regression. We then use these estimated probabilities to calculate the probability of finding a new job by a given quarter after separation conditional on never being recalled as well the probability of being recalled by a given quarter after separation. Note that the sample excludes separators who do not return within eight quarters of the separation; thus, the probability of a job changer finding a new job within eight quarters conditional on not being recalled is one. Standard errors are clustered at the level of the employer in the reference quarter and the dotted lines represent the 95 percent confidence interval. 
Figure 8: Inclusion of Individual-Specific Time Trend

(a) Distressed

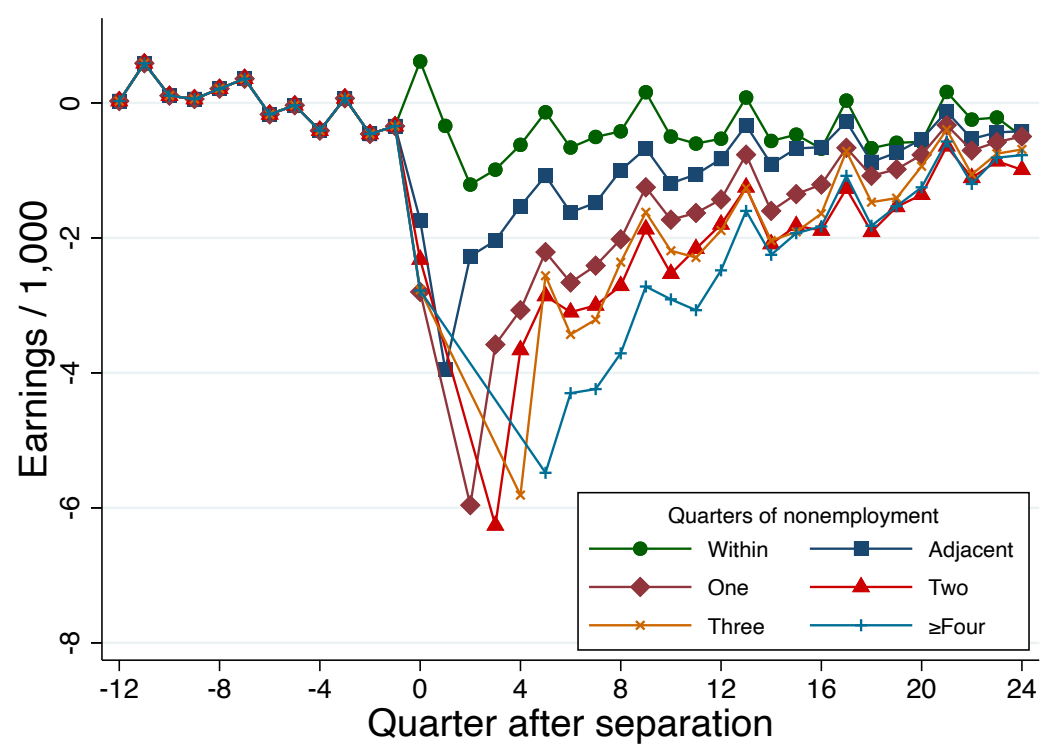

(b) Non-Distressed

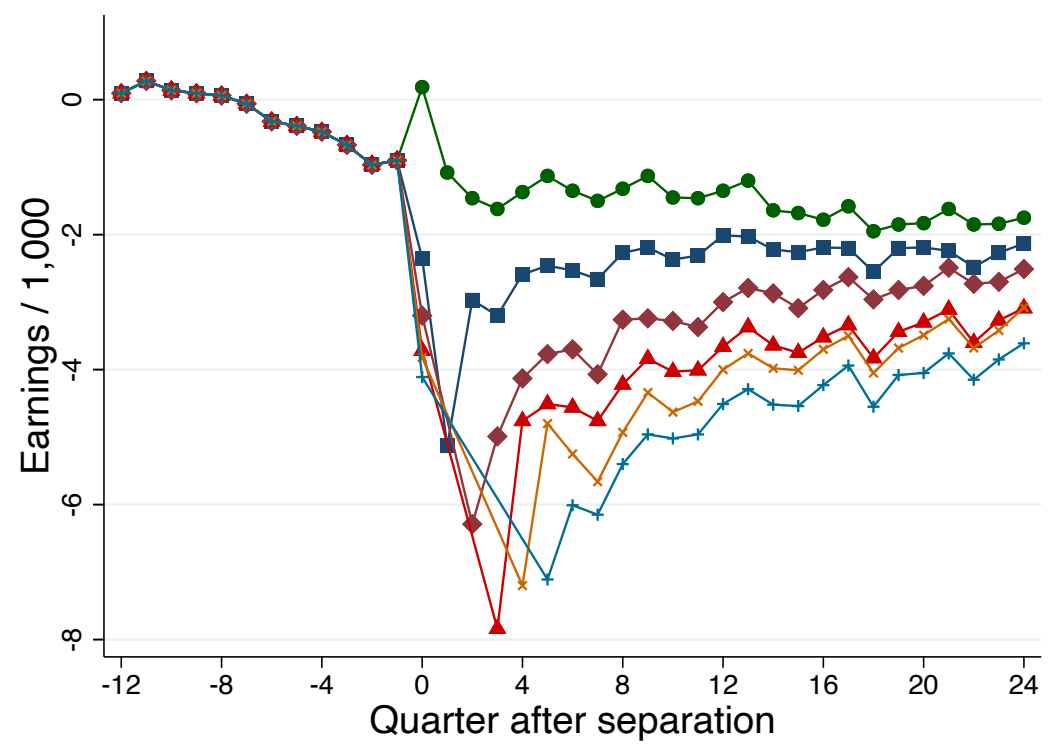

Notes: The figure presents the estimated earnings consequences of a job separation by firm health (distressed and non-distressed) and duration of nonemployment. The results are derived from a sample that excludes recalls but includes all other stayers and separators. The sample corresponds to reference period 2005:2. The figure displays estimates obtained from a modified version of equation (4), which also includes a linear individual-specific time trend. Panels (a) and (b) plot $\delta^{k, 1, N}$ and $\delta^{k, 0, N}$ against the quarter relative to displacement, respectively. Standard errors are clustered at the level of the employer in the reference quarter and the solid gray lines depict the 95 percent confidence interval around the estimates. 


\section{Figure 9: Change in Firm-Level Characteristics}

(a) Firm Fixed Effect

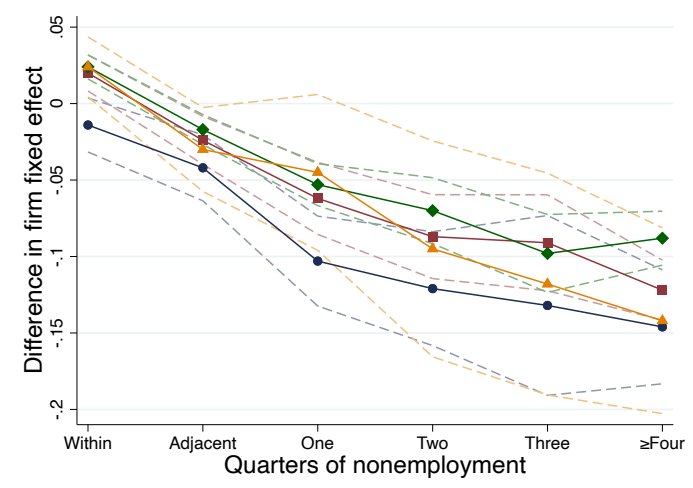

(b) Average Earnings

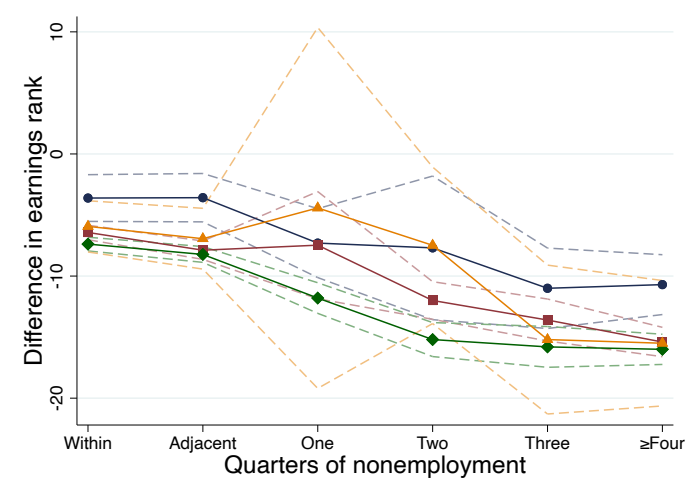

(c) Productivity

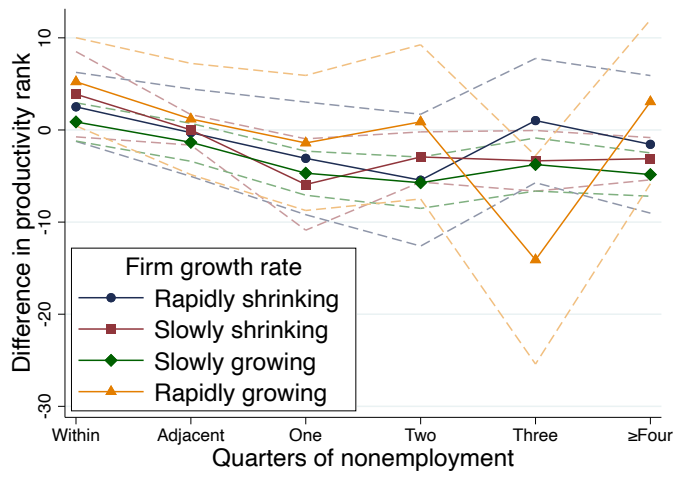

Notes: Each panel presents the predicted change in a different firm-level variable for separators from each growth category, evaluated at the means of the other covariates. The estimates are obtained from equation (5) estimated via Ordinary Least Squares. The outcome variable in panels (a), (b), and (c) are the difference between the destination and origin based on the fixed fixed effect, average earnings rank, and productivity rank, respectively. Within each figure, each line represents the firm growth category and the horizontal axis denotes the duration of time spent in nonemployment prior to re-employment. Standard errors are clustered at the level of the employer in the reference quarter and the dotted lines represent the 95 percent confidence interval. 


\section{Figure 10: Heterogeneity in Change in Firm-Level Characteristics}

(a) Low Firm Fixed Effect

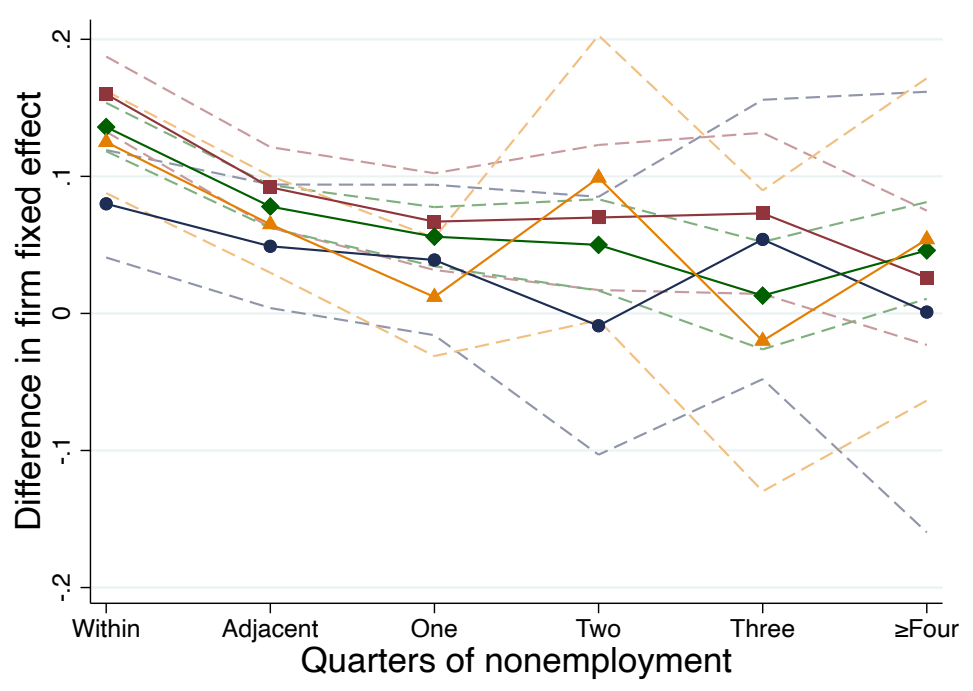

(b) High Firm Fixed Effect

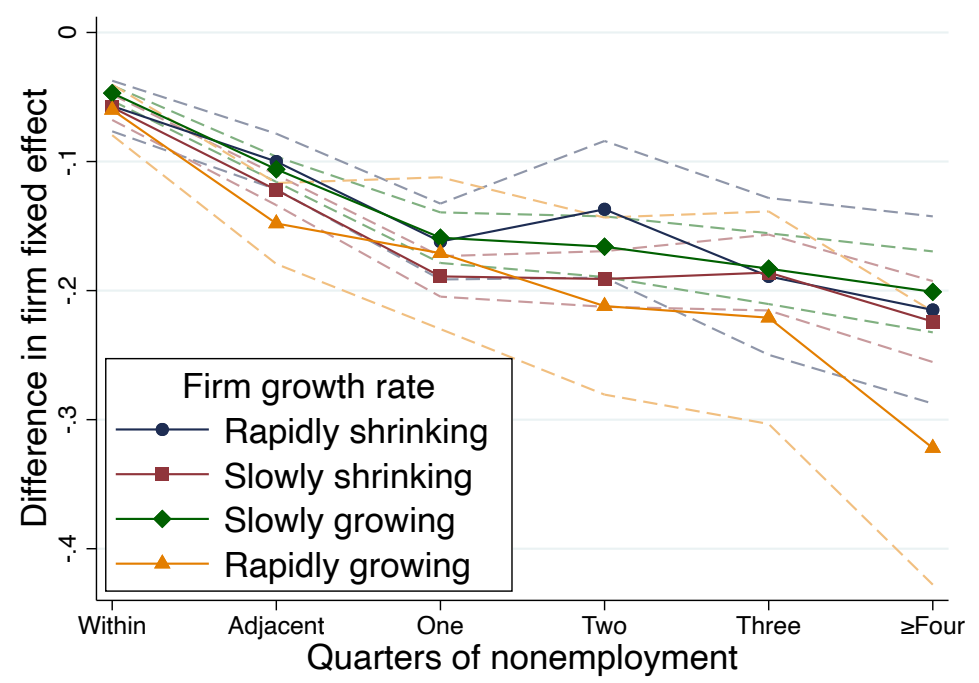

Notes: Panels (a) and (b) present estimates based on a sample of workers whose initial employer has a firm fixed effect that is below and above the sample median, respectively. Each panel presents the predicted difference between the destination and origin based on the fixed fixed effect, evaluated at the means of the other covariates. The estimates are obtained from equation (5) estimated via Ordinary Least Squares. Within each figure, each line represents the firm growth category and the horizontal axis denotes the duration of time spent in nonemployment prior to re-employment. Standard errors are clustered at the level of the employer in the reference quarter and the dotted lines represent the 95 percent confidence interval. 
Figure 11: Duration of Nonemployment by Industry Growth

(a) Weak

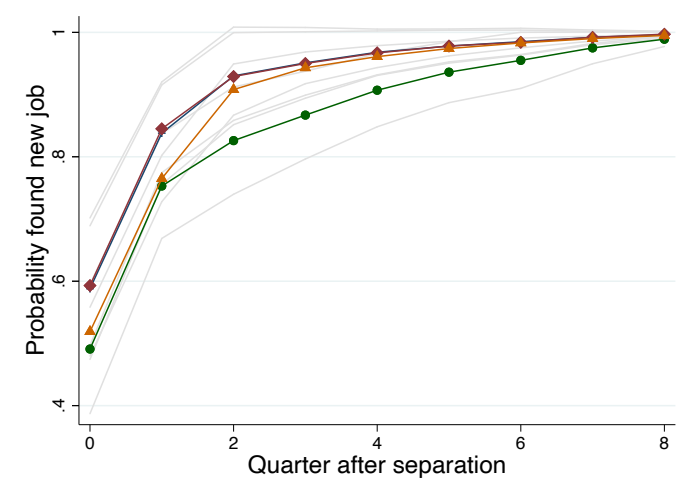

(b) Average

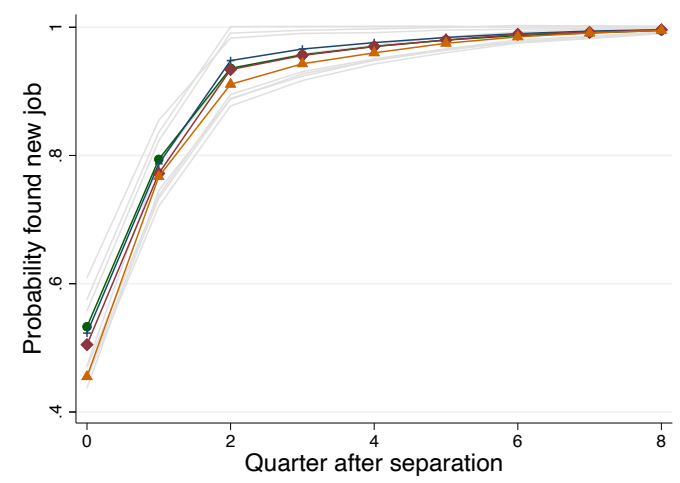

(c) Strong

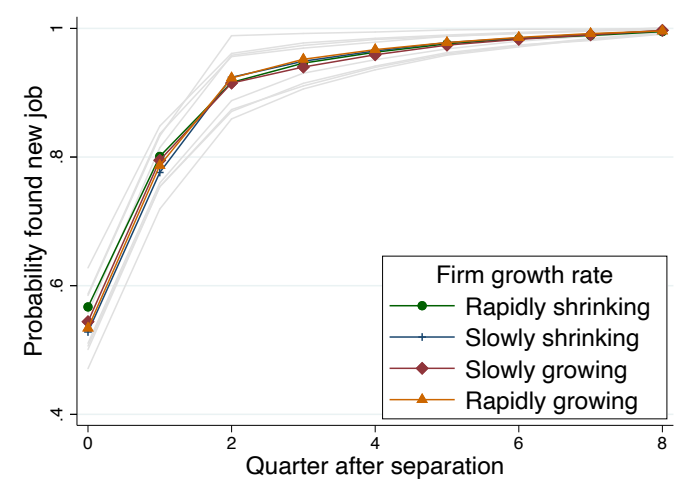

Notes: The figure presents the probability of exiting nonemployment by a given quarter after separation for job changers. The probability of a separator finding a new job in a given quarter after separation and the probability of a separator being recalled in a given quarter after separation are estimated by logistic regression. We then use these estimated probabilities to calculate the problem of finding a new job by a given quarter after separation conditional on never being recalled. Panels (a), (b), and (c) present estimates based on subsamples define by the employment growth rate in the state and industry of the origin employer. Standard errors are clustered at the level of the employer in the reference quarter and the dotted lines represent the 95 percent confidence interval. 


\section{Figure 12: Duration of Nonemployment by Occupation Growth}

(a) Weak

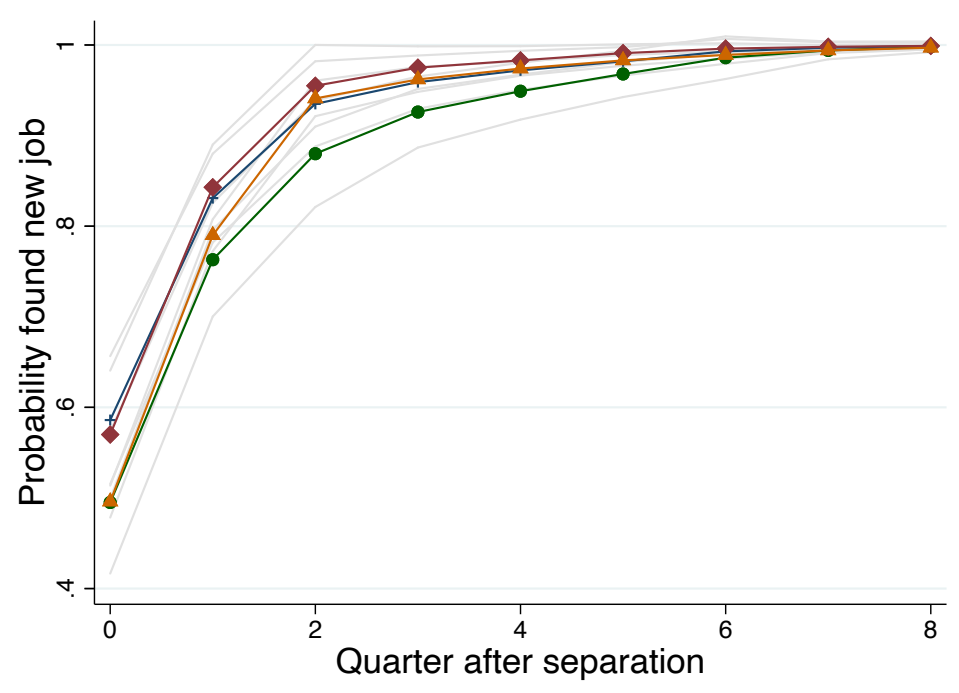

(b) Strong

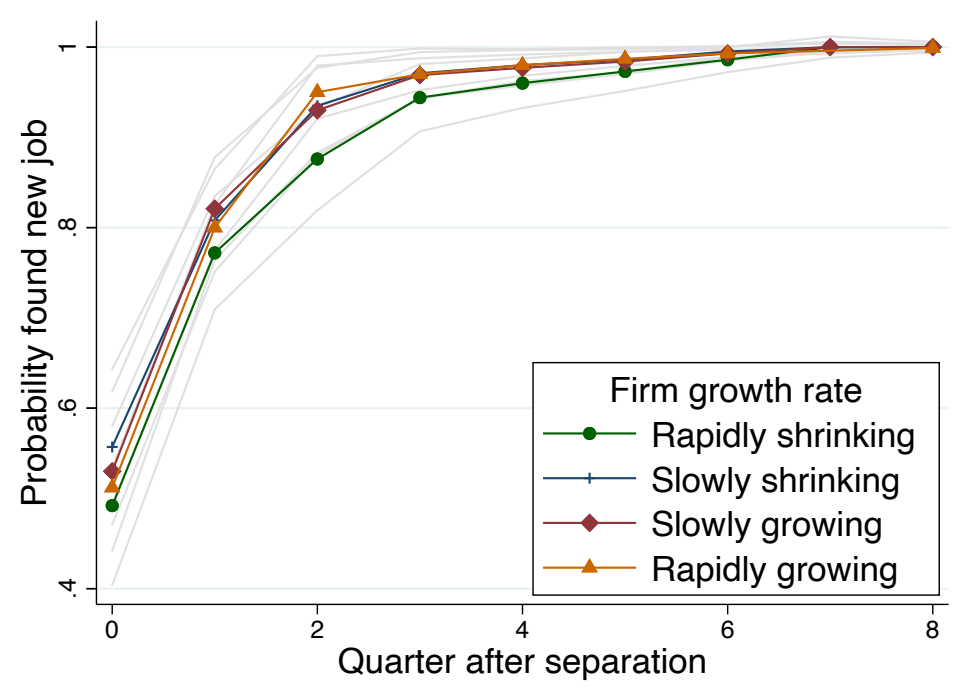

Notes: The figure presents the probability of exiting nonemployment by a given quarter after separation for job changers. The probability of a separator finding a new job in a given quarter after separation and the probability of a separator being recalled in a given quarter after separation are estimated by logistic regression. We then use these estimated probabilities to calculate the problem of finding a new job by a given quarter after separation conditional on never being recalled. Panels (a) and (b) present estimates based on subsamples define by the employment growth rate in the state and occupation of the origin job. Standard errors are clustered at the level of the employer in the reference quarter and the dotted lines represent the 95 percent confidence interval. 


\section{Tables}

Table 1: Descriptive Statistics

\begin{tabular}{|c|c|c|c|c|}
\hline & \multicolumn{2}{|c|}{ Non-distressed } & \multicolumn{2}{|c|}{ Distressed } \\
\hline & $\begin{array}{c}\text { Stayers } \\
\text { (1) }\end{array}$ & $\begin{array}{c}\text { Job } \\
\text { changers } \\
(2)\end{array}$ & $\begin{array}{c}\text { Stayers } \\
(3)\end{array}$ & $\begin{array}{c}\text { Job } \\
\text { changers } \\
(4)\end{array}$ \\
\hline \multicolumn{5}{|l|}{ Age at time of separation } \\
\hline $25 \leq$ age $\leq 34$ & 24.9 & 37.9 & 22.6 & 28.7 \\
\hline $35<$ age $\leq 44$ & 34.8 & 34.7 & 34.8 & 36.4 \\
\hline $45 \leq$ age $\leq 55$ & 40.3 & 27.4 & 42.5 & 34.9 \\
\hline \multicolumn{5}{|l|}{ Sex } \\
\hline Male & 50.5 & 52.1 & 53.5 & 59.6 \\
\hline \multicolumn{5}{|l|}{ Industry } \\
\hline Finance, insurance, and real estate rental and leasing & 7.3 & 8.6 & 3.8 & 5.3 \\
\hline Administrative and support & 3.0 & 5.7 & 4.4 & 8.4 \\
\hline Agriculture, forestry, fishing, and hunting & 0.8 & 0.8 & 2.1 & 1.6 \\
\hline Arts, entertainment, and recreation & 1.4 & 1.6 & 1.3 & 1.0 \\
\hline Construction & 3.2 & 4.2 & 11.3 & 10.6 \\
\hline Manufacturing (durable) & 16.4 & 13.5 & 16.8 & 21.0 \\
\hline Educational services & 14.8 & 9.0 & 21.4 & 5.3 \\
\hline Accommodation and food services & 3.6 & 6.4 & 3.6 & 3.6 \\
\hline Health care and social assistance & 13.9 & 11.5 & 5.6 & 5.4 \\
\hline Information & 4.6 & 5.2 & 2.4 & 3.4 \\
\hline Management of companies and cnterprises & 1.8 & 1.8 & 0.4 & 0.8 \\
\hline Mining, quarrying, and oil and gas extraction & 0.2 & 0.2 & & 0.0 \\
\hline Manufacturing (nondurable) & 3.3 & 3.0 & 7.1 & 7.4 \\
\hline Other services & 1.3 & 1.6 & 2.2 & 2.0 \\
\hline Professional, scientific, and rechnical services & 4.6 & 5.6 & 5.8 & 8.6 \\
\hline Retail trade & 10.7 & 13.6 & 4.0 & 5.5 \\
\hline Transportation and warehousing & 3.7 & 3.3 & 4.0 & 5.2 \\
\hline Utilities & 1.2 & 0.3 & 0.1 & 0.0 \\
\hline Wholesale trade & 4.3 & 4.3 & 3.7 & 4.6 \\
\hline \multicolumn{5}{|l|}{ Firm size } \\
\hline $50 \leq$ firm size $<100$ & 10.6 & 12.6 & 22.5 & 23.8 \\
\hline $100 \leq$ firm size $<500$ & 27.6 & 31.6 & 45.0 & 49.7 \\
\hline $500 \leq$ firm size & 61.8 & 55.8 & 32.6 & 26.5 \\
\hline Observations & 680,000 & 178,000 & 13,000 & 14,000 \\
\hline
\end{tabular}

Notes: The sample includes workers who are employed in 2005:2 with at least three years of tenure at a firm that has at least 50 workers and is located in California, North Carolina, Oregon, Washington, or Wisconsin. A firm is distressed if it experiences a decline in employment by at least 30 percent between 2005:2 and 2006:2. Firm closures are not included in the sample. Stayers are workers who have strictly positive earnings at their initial employer at least until 2006:2. Job changers are workers who separate from their employer in 2005:2 and have strictly positive earnings at a different employer by 2007:2. 


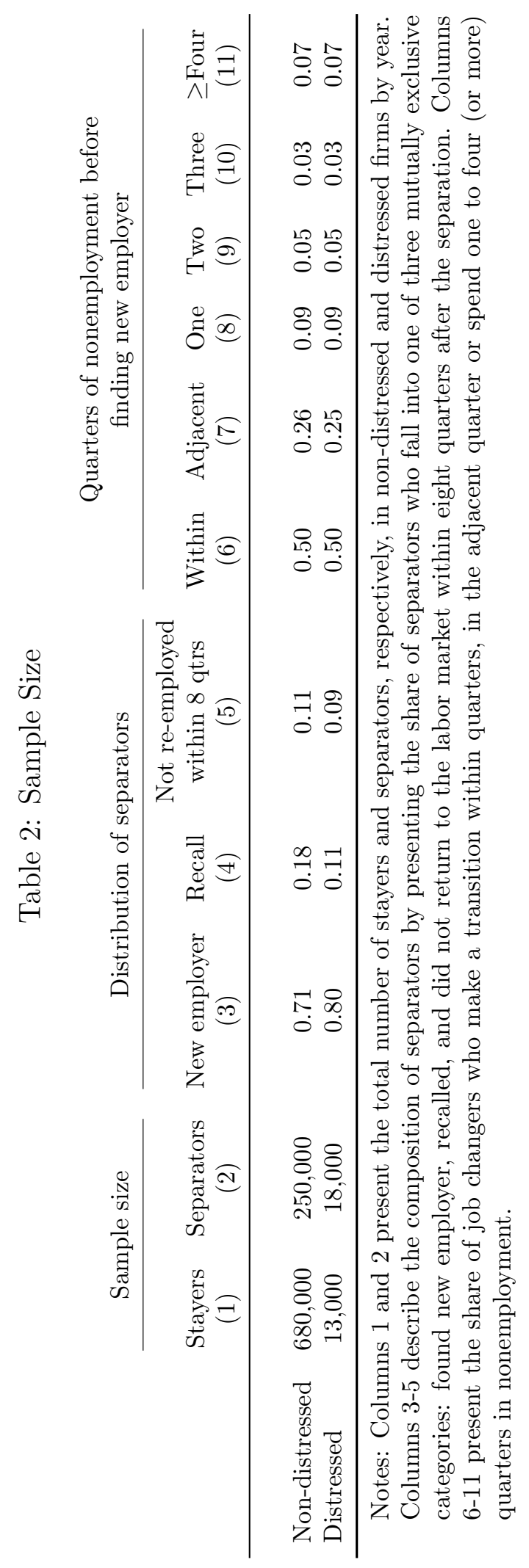


Table 3: Effect of Separation within Subsamples

Quarters of nonemployment

\begin{tabular}{|c|c|c|c|c|c|c|}
\hline & $\begin{array}{l}\text { Within } \\
\text { (1) }\end{array}$ & $\begin{array}{c}\text { Adjacent } \\
(2)\end{array}$ & $\begin{array}{l}\text { One } \\
(3)\end{array}$ & $\begin{array}{l}\text { Two } \\
(4)\end{array}$ & $\begin{array}{c}\text { Three } \\
(5)\end{array}$ & $\begin{array}{c}\geq \text { Four } \\
(6)\end{array}$ \\
\hline \multicolumn{7}{|c|}{ A. Re-employed within four quarters } \\
\hline Distressed & $\begin{array}{l}-356 \\
(174)\end{array}$ & $\begin{array}{l}-1520 \\
(205)\end{array}$ & $\begin{array}{l}-2490 \\
(196)\end{array}$ & $\begin{array}{l}-3240 \\
(307)\end{array}$ & $\begin{array}{l}-3160 \\
(301)\end{array}$ & $\begin{array}{l}-3990 \\
(268)\end{array}$ \\
\hline Non-distressed & $\begin{array}{l}-640 \\
(49)\end{array}$ & $\begin{array}{c}-2030 \\
(71)\end{array}$ & $\begin{array}{l}-3690 \\
(252)\end{array}$ & $\begin{array}{l}-4490 \\
(111)\end{array}$ & $\begin{array}{r}-4800 \\
(157)\end{array}$ & $\begin{array}{r}-5020 \\
(121)\end{array}$ \\
\hline \multicolumn{7}{|c|}{ B. At least five years tenure } \\
\hline Distressed & $\begin{array}{l}-1110 \\
(202)\end{array}$ & $\begin{array}{l}-2400 \\
(243)\end{array}$ & $\begin{array}{l}-3330 \\
(225)\end{array}$ & $\begin{array}{l}-4110 \\
(376)\end{array}$ & $\begin{array}{l}-4040 \\
(383)\end{array}$ & $\begin{array}{l}-4790 \\
(259)\end{array}$ \\
\hline Non-distressed & $\begin{array}{c}-1500 \\
(65)\end{array}$ & $\begin{array}{c}-3070 \\
(74)\end{array}$ & $\begin{array}{l}-4690 \\
(418)\end{array}$ & $\begin{array}{l}-5590 \\
(138)\end{array}$ & $\begin{array}{l}-6140 \\
(225)\end{array}$ & $\begin{array}{l}-6710 \\
(152)\end{array}$ \\
\hline \multicolumn{7}{|c|}{ C. Exclude temporary help industries } \\
\hline Distressed & $\begin{array}{l}-328 \\
(176)\end{array}$ & $\begin{array}{l}-1520 \\
(207)\end{array}$ & $\begin{array}{l}-2500 \\
(198)\end{array}$ & $\begin{array}{l}-3270 \\
(311)\end{array}$ & $\begin{array}{l}-3200 \\
(306)\end{array}$ & $\begin{array}{l}-4110 \\
(226)\end{array}$ \\
\hline Non-distressed & $\begin{array}{l}-642 \\
(50)\end{array}$ & $\begin{array}{c}-2050 \\
(72)\end{array}$ & $\begin{array}{l}-3730 \\
(258)\end{array}$ & $\begin{array}{l}-4540 \\
(113)\end{array}$ & $\begin{array}{l}-4830 \\
(159)\end{array}$ & $\begin{array}{r}-5320 \\
(118)\end{array}$ \\
\hline \multicolumn{7}{|c|}{ D. Pre-separation earnings $>10,000$} \\
\hline Distressed & $\begin{array}{l}-538 \\
(258)\end{array}$ & $\begin{array}{l}-2240 \\
(327)\end{array}$ & $\begin{array}{l}-3670 \\
(323)\end{array}$ & $\begin{array}{l}-5320 \\
(456)\end{array}$ & $\begin{array}{l}-4910 \\
(593)\end{array}$ & $\begin{array}{l}-6290 \\
(389)\end{array}$ \\
\hline Non-distressed & $\begin{array}{l}-789 \\
(72)\end{array}$ & $\begin{array}{r}-2640 \\
(116)\end{array}$ & $\begin{array}{l}-5410 \\
(473)\end{array}$ & $\begin{array}{l}-6640 \\
(177)\end{array}$ & $\begin{array}{r}-7260 \\
(309)\end{array}$ & $\begin{array}{l}-8080 \\
(201)\end{array}$ \\
\hline \multicolumn{7}{|c|}{ E. Men ages $35-44$} \\
\hline Distressed & $\begin{array}{l}-551 \\
(232)\end{array}$ & $\begin{array}{l}-1970 \\
(235)\end{array}$ & $\begin{array}{l}-2900 \\
(264)\end{array}$ & $\begin{array}{l}-3840 \\
(397)\end{array}$ & $\begin{array}{l}-3520 \\
(388)\end{array}$ & $\begin{array}{l}-4650 \\
(302)\end{array}$ \\
\hline Non-distressed & $\begin{array}{l}-803 \\
(68)\end{array}$ & $\begin{array}{c}-2440 \\
(94)\end{array}$ & $\begin{array}{r}-4380 \\
(309)\end{array}$ & $\begin{array}{l}-5080 \\
(152)\end{array}$ & $\begin{array}{l}-5540 \\
(252)\end{array}$ & $\begin{array}{l}-6070 \\
(187)\end{array}$ \\
\hline \multicolumn{7}{|c|}{ F. Women ages 25-34 } \\
\hline Distressed & $\begin{array}{l}-157 \\
(197)\end{array}$ & $\begin{array}{l}-952 \\
(231)\end{array}$ & $\begin{array}{l}-2060 \\
(237)\end{array}$ & $\begin{array}{l}-2550 \\
(337)\end{array}$ & $\begin{array}{l}-2780 \\
(449)\end{array}$ & $\begin{array}{l}-3570 \\
(285)\end{array}$ \\
\hline Non-distressed & $\begin{array}{l}-503 \\
(46)\end{array}$ & $\begin{array}{c}-1620 \\
(66)\end{array}$ & $\begin{array}{l}-3110 \\
(207)\end{array}$ & $\begin{array}{l}-3960 \\
(120)\end{array}$ & $\begin{array}{l}-4130 \\
(129)\end{array}$ & $\begin{array}{r}-4620 \\
(103)\end{array}$ \\
\hline \multicolumn{7}{|c|}{ G. New mothers } \\
\hline Distressed & $\begin{array}{l}-2320 \\
(1230)\end{array}$ & $\begin{array}{l}-1710 \\
(932)\end{array}$ & $\begin{array}{l}-1800 \\
(1550)\end{array}$ & $\begin{array}{l}-2810 \\
(1250)\end{array}$ & $\begin{array}{l}-5700 \\
(1460)\end{array}$ & $\begin{array}{l}-4390 \\
(1280)\end{array}$ \\
\hline Non-distressed & $\begin{array}{l}-2160 \\
(296)\end{array}$ & $\begin{array}{l}-2530 \\
(306)\end{array}$ & $\begin{array}{l}-3890 \\
(288)\end{array}$ & $\begin{array}{l}-4980 \\
(398)\end{array}$ & $\begin{array}{l}-5950 \\
(451)\end{array}$ & $\begin{array}{l}-5910 \\
(247)\end{array}$ \\
\hline
\end{tabular}

Notes: This table presents post-separation earnings changes for separators by growth of the employer (distressed vs. non-distressed) and quarters spent in nonemployemnt. Each panel presents results estimated from a different subsamples that include individuals that: (A) spent less than five quarters in nonemployment after separation, (B) had at least five years of tenure in 2005:2, (C) do not work for firms in the temporary help industry, (D) had average annual earnings that exceed 10,000 in the three years leading up to 2005:2, (E) are male ages 35-44, (F) are female ages 25-34, and (G) are women that give birth in the first three quarters of 2005 or are a stayer. The table summarizes estimates obtained from estimating equation 4 and presents the average post-separation earnings in the four years following re-employment. Standard errors are clustered at the level of the origin firm. 
Table 4: Effect of Separation by Strength of Local Labor Market

Quarters of nonemployment

\begin{tabular}{cccccc}
\hline Within & Adjacent & One & Two & Three & $\geq$ Four \\
$(1)$ & $(2)$ & $(3)$ & $(4)$ & $(5)$ & $(6)$ \\
\hline
\end{tabular}

\begin{tabular}{lcccccc}
\hline A. Industry & & & & & & \\
A.1. Weak & & & & & & \\
Distressed & -164 & -1150 & -1660 & -2970 & -2580 & -2670 \\
& $(257)$ & $(311)$ & $(308)$ & $(433)$ & $(474)$ & $(343)$ \\
Non-distressed & -431 & -2160 & -3800 & -4400 & -3990 & -4900 \\
& $(111)$ & $(112)$ & $(220)$ & $(247)$ & $(176)$ & $(160)$ \\
A.2. Average & & & & & & \\
Distressed & -686 & -1850 & -3180 & -3100 & -4320 & -4230 \\
& $(476)$ & $(579)$ & $(345)$ & $(385)$ & $(756)$ & $(393)$ \\
Non-distressed & -602 & -1670 & -3750 & -4230 & -5020 & -5160 \\
& $(73)$ & $(105)$ & $(121)$ & $(143)$ & $(376)$ & $(188)$ \\
A.3. Strong & & & & & & \\
Distressed & -254 & -1420 & -2450 & -3150 & -2620 & -5000 \\
& $(247)$ & $(243)$ & $(338)$ & $(552)$ & $(418)$ & $(438)$ \\
Non-distressed & -828 & -2300 & -3630 & -4720 & -5120 & -5560 \\
& $(85)$ & $(126)$ & $(492)$ & $(178)$ & $(222)$ & $(211)$ \\
B. Occupation & & & & & & \\
B.1. Weak & & & & & & \\
Distressed & -778 & -1430 & -2180 & -3580 & -3310 & -4190 \\
& $(337)$ & $(300)$ & $(476)$ & $(590)$ & $(692)$ & $(419)$ \\
Non-distressed & -1120 & -2070 & -4070 & -4860 & -4900 & -5560 \\
& $(123)$ & $(186)$ & $(226)$ & $(286)$ & $(348)$ & $(238)$ \\
B.2. Strong & & & & & & \\
Distressed & -175 & -1510 & -1930 & -2250 & -3020 & -4280 \\
& $(373)$ & $(516)$ & $(498)$ & $(549)$ & $(780)$ & $(674)$ \\
Non-distressed & -857 & -1740 & -3620 & -4860 & -5260 & -5280 \\
& $(145)$ & $(227)$ & $(497)$ & $(339)$ & $(453)$ & $(279)$ \\
\hline
\end{tabular}

Notes: This table presents post-separation earnings changes for separators by growth of the employer (distressed vs. non-distressed) and quarters spent in nonemployemnt. Each panel presents results estimated from a different subsample. Panel A defines the subsample based on the employment growth rate of the industry within the state. Panel B defines the subsmaples based on the employment growth rate within the occuption and state. The table summarizes estimates obtained from estimating equation (4) and presents the average post-separation earnings in the four years following re-employment. Standard errors are clustered at the level of the origin firm. 


\section{Sensitivity Analysis on Samples and Specifications with JLS}

We explored a number of differences between our sample design and specification and those of JLS and found them to be unable to explain the difference in our main results. The possible explanations we explored (estimates not reported but available upon request) include:

a. JLS included in their comparison group workers who were observed to separate and later returned to the same employer (recalls), while we omit these individuals.

b. JLS included in their sample separators from firms that closed, while we omit these individuals.

c. JLS restricted their sample to workers with at least six years of tenure, while our tenure restriction is three years.

d. In pooling the sample across dates of separation, JLS hold coefficients constant over time, and therefore across macroeconomic conditions, whereas our separate samples allow those coefficients to vary.

e. JLS's data do not allow them to follow workers who become re-employed in another state, while our data infrastructure allows us to track individuals who cross state lines. ${ }^{1}$

f. JLS include individual time trends in their estimation of specification analogous to (2) in the main text. ${ }^{2}$

This sensitivity analysis suggests that the differences between our results for non-distressed separators and those in JLS are due to the differences in time and place of our data. ${ }^{3}$ The main text has further discussion of this argument including discussion of the related literature.

\section{Winsorization}

Let $\mathrm{Z}_{\mathrm{i}}$ be the greater of the median of earnings observed for individual i 24 quarters before or after the reference quarter and $10,000\left(\mathrm{z}_{\mathrm{i}}=\max \left\{\operatorname{median}\left\{\mathrm{y}_{\mathrm{it}}\right\}, 10000\right\}\right)$. Then define the earnings growth rate for each individual and quarter as:

$$
\Delta_{i t}=\left(y_{i t}-z_{i}\right) /\left[\frac{1}{2} *\left(y_{i t}+z_{i}\right)\right]
$$

The growth rate, $\Delta_{i t}$, captures the extent to which the current earnings exceed the typical earnings of that individual in a given quarter. This growth rate, made popular by Davis et al. (1996) and commonly referred to as the DHS growth rate, is bounded between -2 and 2 . We use this growth rate to identify large increases in quarterly earnings that are likely driven by data errors. The

\footnotetext{
${ }^{1}$ In addition, JLS restricted their sample to workers with positive earnings in every calendar year, whereas we require positive earnings within eight quarters of separation. Von Wachter, Song, and Manchester (2009) show that the earnings losses for non-distressed separators are larger and more persistent when separators with zero annual earnings are included in the sample. JLS also appear to limit their sample of stayers to stayers at firms that experienced some separations. We have not replicated these sample restrictions, but we expect that the differences between them and our restrictions are too small to account for the large difference in estimated outcomes.

${ }^{2}$ The main text Figure 8 shows the impact of including individual specific time trends for our generalized specification (4). In unreported results, we have also included individual specific time trends as a robustness check in estimating (2) and don't find that this makes distressed separators have larger and more persistent earnings losses.

${ }^{3} \mathrm{JLS}$ also did not have the benefit of the extensive data quality controls currently used by the Census Bureau in the LEHD program. The resulting measurement error could also contribute to the difference in findings.
} 
choice of the minimum value of $\mathrm{z}$ as 10,000 is made such that we do not accidentally winsorize earnings for low earners. We chose to edit the earnings values if they exceed the $95^{\text {th }}$ percentile of earnings growth rates such that if we were to recalculate $\Delta_{i t}$ using the edited earnings then $\Delta_{i t}$ would be equal to the $95^{\text {th }}$ percentile of earnings growth rates. Specifically, let $\Delta(p 95)$ be the $95^{\text {th }}$ percentile of $\Delta_{i t}$. The earnings data used in the analysis are equal to:

$$
y_{i t}=\begin{gathered}
y_{i t} \quad \text { if } \Delta_{i t}<\Delta(p 95) \\
z_{i} * \frac{1+.5 * \Delta(p 95)}{1-.5 * \Delta(p 95)} \text { else }
\end{gathered}
$$

Relative to standard winsorization methods that identify outliers in levels, this method has the advantage of correctly retaining the earnings records of high wage individuals.

\section{Inverse Survival Functions}

We start by estimating the logistic regressions presented in equations 7 and 8 . For notational simplicity, let $\mathrm{M}=[1 ; \mathrm{X} ; \mathrm{Z} ; \mathrm{g}]$ be a matrix of the concatenation of all the right-hand-side variables and let $\emptyset_{t}=\left[\alpha_{t} ; \beta_{t} ; \gamma_{t} ; \lambda_{t}\right]$ be the corresponding vector of coefficients. For each $\mathrm{t}$, we use the output from the logistic regression from equation 7 to calculate the baseline probability of finding a new job in that period conditional on not being re-employed prior to $t$ and having a firm of growth rate $\mathrm{g}=[1,2,3,4]$. We denote this conditional probability as, $h_{t}^{n}$, and it is calculated as follows:

$$
h_{t}^{n, g}=\frac{\exp \left(\bar{M}_{t} \widehat{\emptyset}_{t}+\frac{\delta_{g t}}{2}\right)}{\left[1+\exp \left(\bar{M}_{t} \widehat{\emptyset}_{t}+\frac{\delta_{g t}}{2}\right)\right]}-\frac{\exp \left(\bar{M}_{t} \widehat{\emptyset}_{t}-\frac{\delta_{g t}}{2}\right)}{\left[1+\exp \left(\bar{M}_{t} \widehat{\emptyset}_{t}-\frac{\delta_{g t}}{2}\right)\right]}
$$

Where $\bar{M}$ denotes a vector of the mean value of all covariates and $\widehat{\emptyset}_{t}$ is the vector of coefficient estimates from the logistic regression. ${ }^{4}$ Using this same methodology we use the estimates from equation 8 to calculate the condition probabilities for recalls, denoted $h_{t}^{r}$. To summarize, the estimates from the logistic regression allow us to calculate two types of conditional probabilities:

$$
\begin{gathered}
h_{t}^{n, g}=\operatorname{Pr}(\text { new job in } t \mid \text { not reemployed before } t \& \text { firm growth rate } g) \\
h_{t}^{r, g}=\operatorname{Pr}(\text { recall in } t \mid \text { not reemployed before } t \& \text { firm growth rate } g)
\end{gathered}
$$

Note that $h_{t}^{r}=0$ for $\mathrm{t}<2$ by construction.

Using these probabilities we then calculate the following:

$$
\begin{gathered}
h_{t}^{g}=\operatorname{Pr}(\text { reemployment in } t \text { \& firm growth rate } g)=h_{t}^{n, g}+h_{t}^{r, g} \\
P_{0}^{n, g}=\operatorname{Pr}(\text { new job by } t=0 \text { \&firm growth rate } g)=h_{0}^{n, g} \\
P_{t}^{n, g}=\operatorname{Pr}(\text { new job by } t>0 \text { \& firm growth rate } g)=\sum_{\tau=0}^{t}\left(\prod_{s=0}^{\tau-1}\left(1-h_{s}^{g}\right)\right) h_{\tau}^{n, g}
\end{gathered}
$$

\footnotetext{
${ }^{4}$ Note that when we estimate the logistic regression $g=4$ is the reference firm growth rate category. The above notation is consistent with this if you simply assume that $\delta_{4 t}=0$.
} 


$$
P_{t}^{r, g}=\operatorname{Pr}(\text { recall by time } t \text { \& firm growth rate } g)=\sum_{\tau=2}^{t}\left(\prod_{s=0}^{\tau-1}\left(1-h_{s}^{g}\right)\right) h_{\tau}^{r, g}
$$

Lastly, we calculate the probability of finding a new job by time $t$, conditional on never being recalled as:

$$
\operatorname{Pr}(\text { new job by } \mathrm{t} \mid \text { never recalled \& firm growth rate } g)=P_{t}^{n, g} /\left(1-P_{8}^{r, g}\right)
$$

We present the results as an inverse survival plot in which we create a plot in which the $\mathrm{x}$-axis is $\mathrm{t}$ and the $y$-axis is the probability of re-employment by $t$ and we plot four separate lines for the four estimates of $\operatorname{Pr}($ new job by $\mathrm{t} \mid$ never recalled \& firm growth rate $\mathrm{g})$.

\section{AKM Firm Effects}

To estimate the AKM firm fixed effect, we use data on the earnings of all workers who appear in the LEHD between 2002 and 2009. For each worker and each year, we identify the main employer (i.e., the employer that provides at over 50 percent of total earnings in that year) and we calculate the annual earnings associated with that employer in that year as the average quarterly earnings across all quarters in which the worker had strictly positive earnings at the employer. Using these worker by year data we then regress log of annual earnings on an individual fixed effect, a firm fixed effect, year fixed effect, and the interaction between education, sex, and a third-order polynomial in age. ${ }^{5}$ To ease computation burden, we estimate this specification within nine distinct subsamples defined by the Census region in which the firm is located. Within each of these samples, we limit the sample to the largest connected set. To make the firm fixed effects comparable across Census regions, we normalize firm fixed effects by subtracting the mean value of the firm fixed effect for firms in the accommodation and food services industry. This normalization assumes that firms in this industry off a pay premium of zero, on average.

\section{Firm Productivity}

We measure firm productivity using revenue and employment data from the Census Business Registrar and the Longitudinal Business Database (LBD). We measure productivity as log revenue per worker, which is a measure that has been commonly used to measure productivity at both the macro and micro level. While this is a relatively crude measure of productivity compared to Total Factor Productivity (TFP), other research has found log revenue per worker is highly correlated with TFP within industries. We measure the productivity of each firm as the employmentweighted log revenue per worker between 2002 and 2009. We then calculate employmentweighted ranks within four-digit North America Industry Classification System (NAICS) industry codes. We are able to measure log revenue per workers for approximately 80 percent of firms in the LBD and the ranks are calculated within the universe of firms for which we can measure productivity between 2002 and 2009.

\footnotetext{
${ }^{5}$ To identify both year and age effects, we center age around 40 and include a quadratic and cubic transformation of age but omit the linear term.
} 